\title{
Molecular anatomy and functions of the choroidal blood-cerebrospinal fluid barrier in health and disease
}

\author{
Jean-François Ghersi-Egea ${ }^{1}$ (D) Nathalie Strazielle ${ }^{1,2} \cdot$ Martin Catala $^{3} \cdot$ Violeta Silva-Vargas $^{4} \cdot$ Fiona Doetsch $^{4}$. \\ Britta Engelhardt ${ }^{5}$
}

Received: 7 November 2017 / Revised: 7 January 2018 / Accepted: 13 January 2018 / Published online: 24 January 2018

(c) The Author(s) 2018. This article is an open access publication

\begin{abstract}
The barrier between the blood and the ventricular cerebrospinal fluid (CSF) is located at the choroid plexuses. At the interface between two circulating fluids, these richly vascularized veil-like structures display a peculiar morphology explained by their developmental origin, and fulfill several functions essential for CNS homeostasis. They form a neuroprotective barrier preventing the accumulation of noxious compounds into the CSF and brain, and secrete CSF, which participates in the maintenance of a stable CNS internal environment. The CSF circulation plays an important role in volume transmission within the developing and adult brain, and CSF compartments are key to the immune surveillance of the CNS. In these contexts, the choroid plexuses are an important source of biologically active molecules involved in brain development, stem cell proliferation and differentiation, and brain repair. By sensing both physiological changes in brain homeostasis and peripheral or central insults such as inflammation, they also act as sentinels for the CNS. Finally, their role in the control of immune cell traffic between the blood and the CSF confers on the choroid plexuses a function in neuroimmune regulation and implicates them in neuroinflammation. The choroid plexuses, therefore, deserve more attention while investigating the pathophysiology of CNS diseases and related comorbidities.
\end{abstract}

Keywords Blood-cerebrospinal fluid barrier - Blood-brain barrier - Choroid plexus - Stem cell $\cdot$ Brain development . Lymphocyte $\cdot$ Transporters $\cdot$ Inflammation $\cdot$ Tight junction

\section{Introduction}

The cerebrospinal fluid (CSF) is separated from the blood by barriers located at the choroid plexuses and at the arachnoid membrane situated downstream of CSF flow. This article focuses mainly on the choroid plexuses. The arachnoid and other meningeal membranes are reviewed in a separate article in this issue.

Jean-François Ghersi-Egea

jean-francois.ghersi-egea@inserm.fr

1 Fluid Team, Lyon Neurosciences Research Center, INSERM U1028, CNRS, UMR5292, University Lyon-1, Lyon, France

2 Brain-i, Lyon, France

3 UPMC, CNRS UMR7622, INSERM ERL 1156, Paris, France

4 Biozentrum, University of Basel, Basel, Switzerland

5 Theodor Kocher Institute, University of Bern, Bern, Switzerland
The choroid plexuses are richly vascularized veil-like structures located in the ventricular system of the brain. They are responsible for the secretion of a large proportion of CSF. The secretion of this fluid constitutes the first discovered function of the choroidal tissue. The functions of the choroid plexuses in relation to CNS homeostasis largely extend beyond this important secretory activity. Their unique location within the two lateral, the third and the fourth ventricles of the brain, their peculiar structural organization as a tight epithelial barrier surrounding fenestrated vessels, and the various transport and secretion pathways active in the choroid plexus epithelial cells, make them ideal structures to control the molecular and cellular composition of CSF and brain fluids. As a correlate, the implication of the choroid plexuses in the pathophysiology of different CNS diseases is probable and deserves more attention. This article describes our current understanding of the developmental origin of the choroid plexuses, the roles played by choroid plexuses for smooth brain development and function, their potential 
involvement in brain surveillance and repair, and the impact of choroid plexus dysfunctions in selected CNS diseases.

\section{Choroid plexus morphology and connection to brain fluid compartments}

\section{Choroid plexus morphology in relation to blood-CSF exchanges}

The choroid plexuses form an interface between two circulating fluids, the blood and the CSF. All choroid plexuses are constituted by a cuboidal epithelium with numerous villi that ensheathes a connective stroma. Blood vessels penetrate this stroma and form large fenestrated capillary loops juxtaposed to the tight epithelium that constitutes the blood-CSF barrier (BCSFB) per se. Different types of immune cells are associated with the choroid plexuses, both in the stroma and adhering to the CSF-facing membrane of the epithelial cells. Three factors favor the exchanges between the blood and the CSF across the choroid plexuses. First, the choroidal local blood flow is very high, around $4 \mathrm{ml} \mathrm{g}^{-1} \mathrm{~min}^{-1}$, actually the highest found in the brain [153]. This results from an extensive network of wide and anastomosed capillaries throughout the choroidal stroma (Fig. 1a). Second, the choroidal endothelium that forms the first cellular layer between the blood and CSF (Fig. 1b) is highly permissive to a large range of molecules. The extent to which the paracellular pathway at this endothelium is sealed remains unclear (see infra), but the diaphragmed fenestrations that are landmarks of the
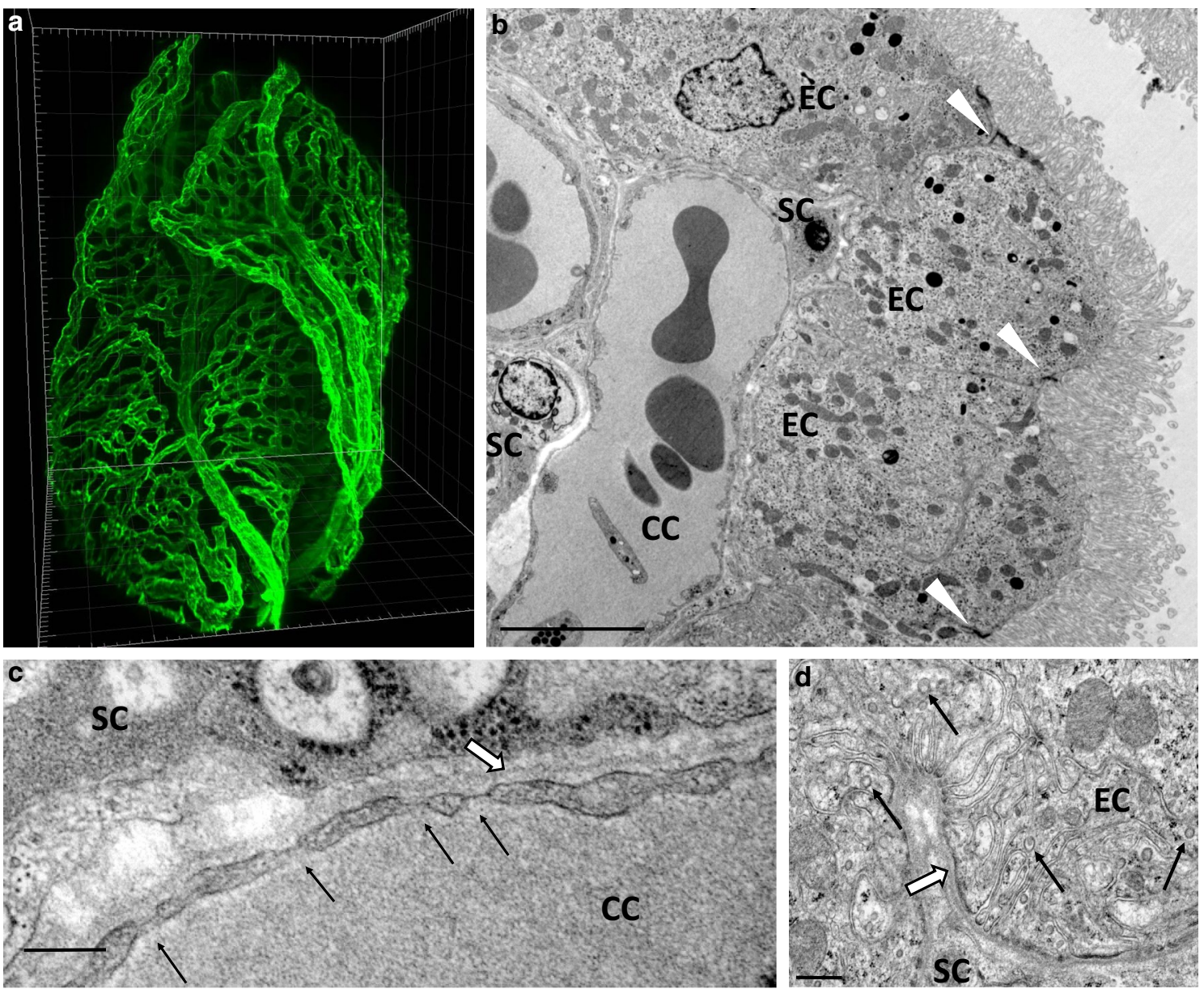

Fig. 1 Vascularization and morphological characteristics of the choroid plexuses. a Three-dimensional representation of the vascular network of a large choroid plexus villus. Choroidal vessels are labeled using an antibody directed against reca- 1 , and the choroidal tissue (here dissected from the lateral-ventricle of a rat brain) is imaged by light sheet fluorescence microscopy. Note the dense anastomosed capillary network. The stromal cells and epithelial monolayer are not visible in the image. Small graduations are $10 \mu \mathrm{m}$ apart. b, c, d Electron microscopy showing the cellular organization of a choroid plexus villus. Epithelial cells (EC) covered by a dense apical border of microvilli and containing numerous mitochondria are sealed by tight junctions (white arrowheads), and are apposed to stromal cells (SC) and choroidal capillaries (CC). Higher magnification in $\mathbf{c}$ illustrates endothelial fenestrations (arrows). Higher magnification in $\mathbf{d}$ illustrates basolateral infoldings where numerous transport vesicles (arrows) are forming. White arrows in $\mathbf{c}$ and $\mathbf{d}$ point to the endothelial and epithelial basement membranes, respectively. Bar $5 \mu \mathrm{m}$ (b), $200 \mathrm{~nm}(\mathbf{c}), 500 \mathrm{~nm}(\mathbf{d})$ 
choroidal capillary loops (Fig. 1c) allow a facilitated diffusion into the stroma of molecules with molecular weight up to $\sim 800 \mathrm{kDa}$ (reviewed in [149]). The formation and maintenance of the fenestrations and their diaphragms involve the plasmalemma vesicle associated protein (Plvap) gene [143] and are under the control of the choroidal epithelium via a basolateral secretion of vascular endothelial growth factor (VEGF). Neutralizing choroidal VEGF production leads to strong morphological and functional alterations of the choroidal vasculature, with presumable consequences on CSF secretion and composition [86]. This mechanism may underlie the central side effect of anti-VEGF antibodies observed in some patients under antitumoral therapy. Third, the choroidal epithelial cell membranes display basolateral infoldings and apical microvilli (Fig. 1b, d) that greatly increase the surface area available for transfer between the stroma and the CSF [66]. Extrapolating rodent surface measurements to the adult human, the apical surface developed by the epithelium of the four choroid plexuses represents $10 \%$ of the surface area developed by the brain microvasculature forming the blood-brain barrier (BBB). The exchanges across the choroidal epithelium are, however, highly regulated. They can be facilitated for various nutrients, micronutrients, hormones, polypeptides, or restricted for many other compounds, by the combined action of tight junctions, transport processes and metabolic enzymes. This implies high-energy requirements as illustrated by the presence of numerous mitochondria in the choroidal epithelial cells. Thus, the BCSFB should be viewed as an active interface rather than a simple barrier. Such an array of transport regulatory mechanisms would be rather unexpected if CSF was only fulfilling the usually cited buoyancy role and sewer function for brain metabolites. It makes more sense in the light of the current understanding of CSF functions, which go far beyond a drainage function.

\section{The cerebrospinal fluid compartments and volume transmission}

The CSF is contained within the boundaries formed by the barriers separating the CNS from the blood. This fluid is, therefore, an integral part of the CNS, and is renewed several times a day. It circulates through the ventricular system into the vela such as the velum interpositum, the internal cisternal spaces such as the ambient cistern, and into the external subarachnoid spaces surrounding the brain and spinal cord. These cisternal and subarachnoid spaces, illustrated in [48, 129], are characterized by a complex leptomeningeal membrane network in which blood vessels are running. These CSF spaces are connected to the perivascular spaces (PVS) surrounding the vessels penetrating the brain parenchyma. The anatomical organization of this CSF-PVS connection differs according to the vessel type (veins versus arteries) and the brain area. In particular, one or two cell layers of leptomeningeal origin extend along the penetrating arteries, and complexify CSF/perivascular fluid exchanges [171]. Exchanges of solutes between the CSF and the extracellular fluid occur also across the permissive ependyma, and across the less permissive glia limitans bordering the outer boundaries of the brain [48]. Extensive deep brain parenchyma diffusion of a substance is not expected following intraventricular or intrathecal bolus infusion. The pattern of brain penetration from the CSF can, however, be much broader when considering substances continuously secreted by the choroid plexuses into the CSF and associated perivascular fluid. An example is transthyretin, a carrier protein involved in the regulation of thyroid hormone concentration in the extracellular fluids. In the brain, transthyretin is uniquely secreted by choroid plexus epithelial cells into the CSF in a continuous manner and throughout life [117], allowing long-term diffusion within the neuropil. Periventricular cellular uptake from CSF followed by retrograde transport also occurs, as exemplified for manganese [4, 12]. Circumventricular organs (CVOs) which are either sensing or secreting organs interacting with the peripheral blood are juxtaposed to CSF spaces and a specific CSF-CVO dialogue takes place across the tanycytes bordering the CSF side of CVOs [65, 95].

The functions of the CSF are, therefore, multiple. They include the overall drainage of brain metabolites diffusing into the CSF, inorganic ion osmoregulation, and $\mathrm{pH}$ buffering for the brain extracellular fluid [108]. They also include a role in volume transmission of different biologically active compounds and micronutrients within the brain, a function that is particularly relevant to brain development. The proportion of CSF is especially large during brain development [46], stem cells are lining the ventricles, and the CSF bears various trophic and differentiation factors, guidance molecules, some of them secreted by the choroid plexus cells themselves (see infra). This volume transmission function remains significant in adulthood for the maintenance of brain homeostasis, and likely for brain repair. At the ventricular level, it benefits from an organized pattern of cilia modules whose beating controls substance distribution along the ependymal wall [43].

\section{The cerebrospinal fluid compartments and CNS immune privilege}

Understanding the immune privilege of the CNS requires appropriate consideration of CNS anatomy, especially regarding the localization and the different functions of the respective endothelial, epithelial and glial brain barriers, as these establish various CNS compartments that significantly differ in their communication with the peripheral immune system [40]. Taking brain barriers into account, one can 
appreciate that the CNS parenchyma proper is an immune privileged site according to its original definition, namely a site in which experimentally implanted tissue allografts are incapable of provoking an immune response leading to their rejection. The immune privileged status of the CNS parenchyma has been further substantiated by observations that viral antigens introduced into the CNS parenchyma evade immunological recognition. In fact, the CNS parenchyma also lacks the ability to mount a rapid innate immune response when exposed to bacterial products or experimentally induced cell death, which in peripheral organs triggers the rapid infiltration of neutrophils and macrophages (summarized in [40]). The afferent arm of the immune system, i.e. immune cell entry into the CNS parenchyma, is prohibited by the glia limitans surrounding the entire CNS parenchyma. The efferent arm of the CNS parenchymal immune system is limited as the resident tissue macrophages, the microglial cells, do not migrate to peripheral draining lymph nodes to present antigens, and thus only CNS parenchymal antigens reach the draining lymph nodes via interstitial fluid [37]. The CNS parenchyma proper is thus protected from the immune system. This is very different from the ventricular and subarachnoid CSF spaces, which do not exhibit the same immune privileged status as the CNS parenchyma proper. Allografts transplanted directly into cerebral ventricles are readily rejected (summarized in [40]). Furthermore, the CSF drains along lymphatic vessels that pass through the cribriform plate and the dura mater into deep cervical lymph nodes (summarized in [40]). This pathway also allows for the trafficking of immune cells from the CSF space to CNS draining lymph nodes, thereby establishing fully functional afferent connections of the immune system with the CNS.

The immune privilege of the CNS is thus established by its specific morphological architecture, which we have previously proposed to resemble the architecture of a medieval castle that is surrounded by two walls embracing a castle moat [38]. Using this comparison, the epithelial choroidal epithelium and the arachnoid membrane establish the outer wall of the castle, which in the case of peripheral danger followed by peripheral immune cell activation, can be breached by activated immune cells in search of their specific antigen in the CNS [129]. Within the CSF-drained space-the "castle moat"- the immune cells encounter antigen-presenting cells- "castle-moat guards"-, which are exposed to CNS antigens within the CSF-drained subarachoid space and the ventricles. If immune cells encounter their specific antigen on these "castle moat" antigen presenting cells, they will be reactivated allowing them to cross the second wall made of the perivascular and superficial glia limitans, and subsequent entry into the CNS parenchyma, the "castle" proper [1] to fight against dangers and infections.

In light of these well-recognized and newly documented functions of the CSF, the choroid plexuses located upstream of the CSF circulation become important actors of both molecular and cellular exchanges between the blood and the CNS, and a relevant source of biologically active molecules for the developing and adult brain. They appear as main CNS sensors for insults of both peripheral and central origin. Their role in protecting the CSF against homeostatic changes and toxic challenges also becomes crucial to prevent dysfunction of volume transmission and immune surveillance within the brain (Fig. 2). Our current understanding of these choroid plexus functions are described in the next sections.

\section{Understanding choroid plexus development}

The choroid plexuses are composed of both an apical epithelium and a stromal connective core (Fig. 3a). The choroidal epithelium lies in continuity with the ependyma suggesting that these two cell layers arise from the same embryonic structure. The mesenchymal core of the plexus evaginates into the ventricular lumen from the leptomeninges, suggesting a common embryonic origin of these two structures.

The definitive proof of the neural tube origin of the choroid plexus epithelium was obtained from interspecies grafts in birds: the plexus of the lateral ventricles originates from the prosencephalon [22], the plexus of the third ventricle from the diencephalon [5], the plexus of the 4th ventricle from the rhombencephalon [87] (Fig. 3b). The origin of the cephalic meninges was also investigated using interspecies grafts in birds. The meninges of the forebrain are derived from the neural crest [29], whereas brain stem meninges are produced by the cephalic mesoderm (i.e., the unsegmented portion of the paraxial mesoderm located rostrally to the first somite) [28] (Fig. 3c). It should be noted, however, that the endothelial cells of the stromal vessels from the forebrain choroid plexuses originate from the cephalic mesoderm and not from the neural crest as the rest of the connective tissue of the stroma [27]. In mice, such a dichotomy in the origin of the sus- and sub-tentorial meninges (and choroidal stroma) was also demonstrated [92].

A myeloid population is present in the choroid plexus: stromal macrophages, stromal dendritic cells, stromal myeloid progenitors [100, 101, 133], and epiplexus Kolmer cells located at the apical surface of the choroidal epithelium (Fig. 3d). These cells are little studied as evidenced by the absence of their description in most classic histology textbooks. However, very recently, their origin has been highlighted. These cells have a dual origin: some derive from the myeloid progenitors generated by the yolk sac in the earliest stages of embryogenesis. In addition, a continuous replacement is observed by cells from the bloodstream [52] or from stromal progenitors [100]. Thus, macrophagic cells of the choroid plexus stroma differ from meningeal macrophages, 


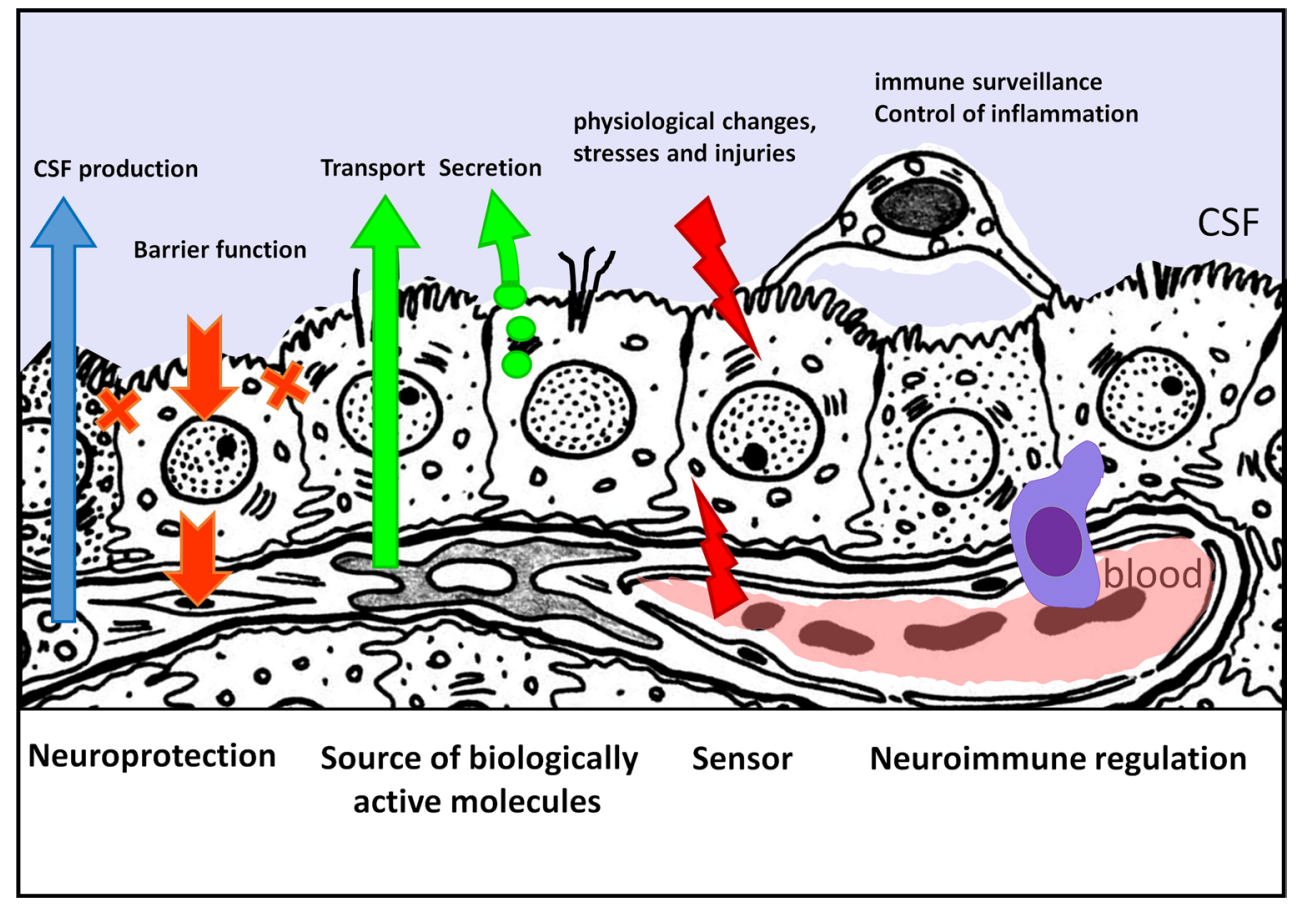

Fig. 2 Cartoon representing the main choroid plexus functions. Neuroprotective functions result from the capacity of the choroid plexus epithelium to secrete the CSF (blue arrow) that allows maintenance of brain homeostasis, and from its ability to prevent the entry or increase the efflux of various deleterious compounds. The latter aspect involves the combined action of efflux transporters and tight junctions that seal the paracellular pathway (orange arrows and crosses). The choroid plexus is also an important source of biologically active molecules involved in brain development, stem cell differentiation and brain repair, that are either transported from blood or synthetized by the epithelium (green arrows). The stromal and epithelial choroid plexus cells are sensitive to physiological changes in brain homeostasis and to peripheral or central insults such as inflammation (red arrows), often responding by a rapid secretion of chemokines. This sentinel function, and their implication in the control of immune cell traffic between the blood and the CSF (blue cell) confer to the choroid plexuses a function of neuroimmune surveillance of the brain that is reinforced when the organism is challenged macrophages of the perivascular spaces and microglia which are stable resident populations.

Molecular control of the development of the choroid plexuses is only beginning to be revealed, and has focused on the plexus of the 4 th ventricle or of the lateral ventricles. The epithelium of the choroid plexuses develops from the dorsal region of the neural tube. $G d f 7$ encodes a protein secreted by this region. The lineage of cells expressing $G d f 7$ shows that this population generates all the epithelial cells of the choroid plexuses of the third and fourth ventricles and only the anterior part of the plexuses of the lateral ventricles [30]. The posterior part of these plexuses originates from a region not expressing $G d f 7$ but whose differentiation is dependent on the tissues expressing this gene [30]. The Otx2 gene, which encodes a transcription factor containing a homeodomain important for the development of the CNS, plays a major role in the formation of the plexuses. Indeed, the four plexuses are absent after conditional deletion of this gene at E9 in mice [64]. Both proliferation and differentiation of choroidal epithelial cells are dependent on Notch signalling and neurogenin2 [60]. In fact, the situation is very complex because some molecules play a role for some anatomical sites and not for others. At present, we do not have a detailed molecular characterization of the dynamics of plexus formation. It is, however, interesting to note that some factors involved in this formation also play a role in tumors derived from the choroid plexus such as TWIST A, TRPM3 [58, 62].

During human development, choroid plexuses undergo several morphological modifications known as maturation or differentiation. The conventional classification, which is still widely used was first described by Shuangshoti and Netsky [136]. It deserves to be completed and nuanced. Nevertheless, because it is still widely used today, we outline it below. Choroid plexuses develop differently depending on their ventricular location. We will describe first the development of the plexuses of the lateral ventricles and then we will specify some of the characteristics of the third and fourth ventricle plexuses.

- Stage I corresponds to the infolding of the two presumptive territories of the choroid plexus bulging into the lateral ventricles. These two rudiments are separated by a thin median structure forming the choroidal or ventricular roof. The epithelium is pseudo-stratified with cen- 
Fig. 3 Developmental origin and features of the choroid plexus components. a Section of a human telencephalic choroid plexus in a fetus near term. The epithelium of the choroid plexus lies in continuity with the ependyma. Leptomeninges bulge into the ventricular cavity and form the plexus mesenchyme. b Section of a chimera in which the neural tube of a quail has been transplanted in a chick embryo. The epithelium of the choroid plexus (arrows) derives from quail (recognized by QH1 antibody). c Section of a chimera in which the cephalic mesoderm of a quail has been transplanted into a chick host. Quail endothelial cells (arrows) recognized by MB1 antibody populate the mesenchyme of the plexus. d Diagram from an electron microscopy showing the surface of the epithelium of the choroid plexus and displaying Kolmer cell. b and c Photographs due to the courtesy of Dr. Anne Grapin-Botton, d drawing by M Catala
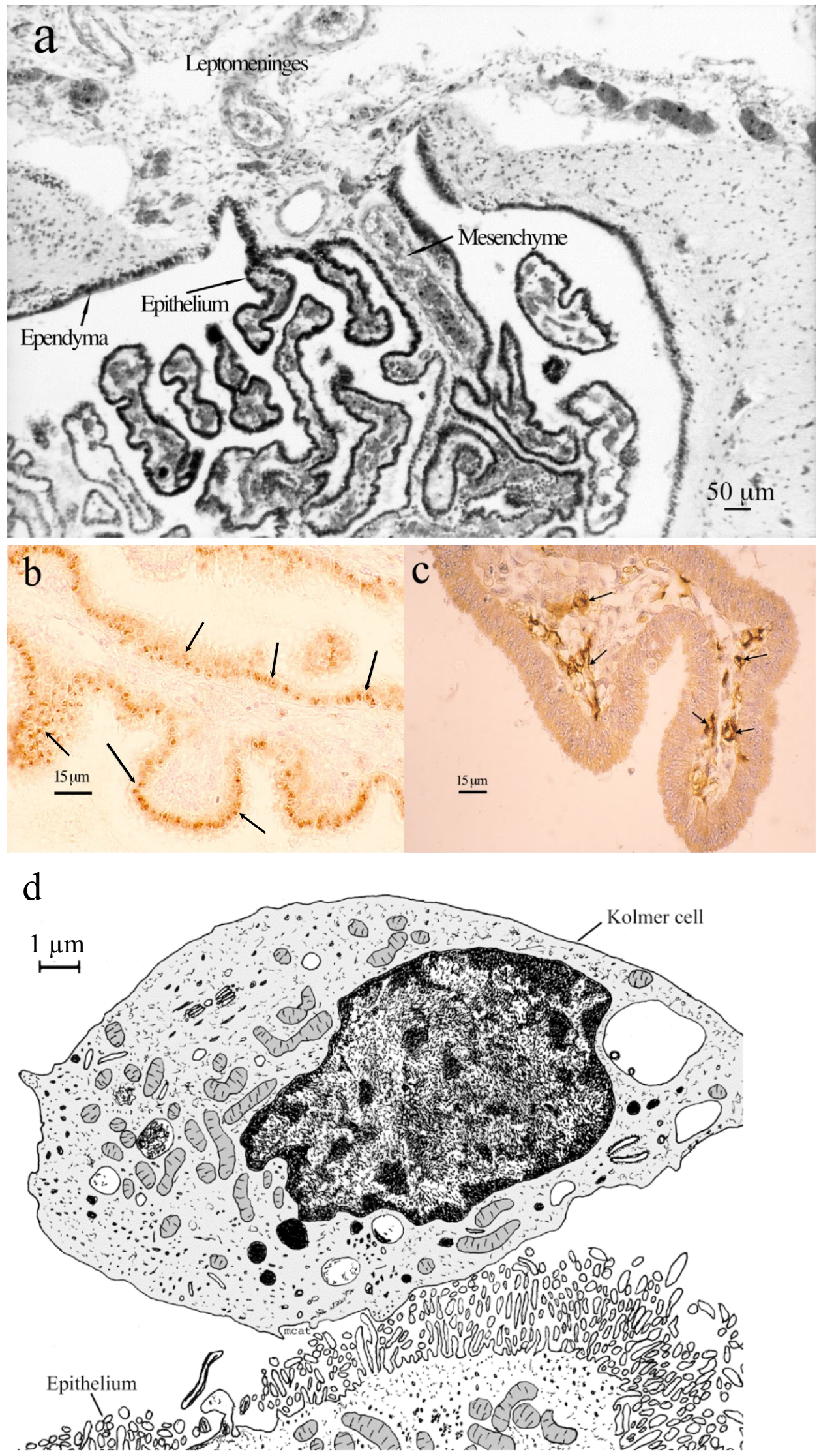
trally located ovoid nuclei. The mesenchymal tissue of the stroma is very loose, the vessels still have thin walls and are poorly individualized. Red blood cells are still nucleated. This stage lasts from the 7th to the 9th week of development in human.

- Stage II is characterized by a progressive and extensive growth of the choroid plexus. At the 11th week of development, the telencephalic choroid plexus occupies practically the entire ventricular volume. The choroidal epithelium is unistratified, low prismatic. The basal pole of the cells is filled with glycogen granules (which are only detected after fixation with alcoholic formaldehyde because the glycogen is soluble in water). This abundance of glycogen leads to the apical localization of the nucleus in the cell. The mesenchyme is still loose with the presence of mucin and mucopolysaccharides forming spaces or pseudo-cysts; collagen fibers are scarce. Tubular epithelial structures are present in the stroma representing pinched-off surface epithelium within the mesenchyme. This stage lasts from the 9th to the 16th week of development in human.

- Stage III is accompanied by the development of numerous villi which gives a highly branched appearance to the choroid plexus. The amount of glycogen decreases in cells, whose form becomes cubic, their nucleus takes a central position or remains more apically. In the mesenchyme, the tubules are numerous and collagen fibers accumulate. This stage lasts from the 17th to the 28th week of development in human.

- The last fetal stage or stage IV lasts from the 29th week of development until the end of the pregnancy. The size of the epithelial cells further decreases, the nuclei become localized to the basal pole. The amount of collagen fibers continues to increase in the plexus stroma.

The choroid plexuses of the third and fourth ventricles develop without passing through stage I. They are born from the roof of the neural tube, the epithelium of which is very flat, in contrast to that which gives rise to the plexuses of the lateral ventricles. The level of intracellular glycogen is less abundant than that of the plexuses of the lateral ventricles, and their maturation is also faster.

The conventional classification described above deserves to be updated with the aid of more modern techniques. Recently, the behaviour of apical cilia of choroidal plexus epithelial cells was analysed during development in mice [102]. Cilia are initially immotile and begin to move around the 15th embryonic day (E15), with the maximal motility observed on the second postnatal day (P2). This motility disappears completely at P14. The total number of cilia per cell nevertheless remains constant throughout this period. This transient acquisition of motility is concomitant with a transient expression of the Dnahcll gene, which codes for an axonemal dynein essential for ciliary motility. Nothing is known in humans concerning these phenomena but this deserves to be investigated.

A second approach that could provide further molecular insight into the maturation of choroid plexuses would be to perform transcriptome analysis of the cells of these organs. Such an approach has already been performed in adult mice [89] and rats [111]. To the best of our knowledge, the only prenatal study comparing choroid plexuses according to their localization during development was performed in a unique stage of mouse fetuses (E18.5) [85]. The authors studied the genes expressed in both the telencephalic and the 4th ventricle choroid plexuses. They showed that both types of plexuses express common genes but also genes that are region specific. It would be interesting to carry out a transcriptomic study throughout embryonic and fetal development to see if the expressed genes allow a new classification of maturation stages. Indeed, such an approach has already been successfully applied to define new stages of lung maturation in humans. Importantly, claudin proteins are expressed at the junctions linking the epithelial cells in the nascent choroid plexus in human, and evidence of the tightness of these junctions has been provided in embryonic rodents ([74, 80], and see infra). This suggests that the barrier originates as early as the choroid plexus develops. The mechanism specifically regulating the developmental expression and function of tight junction proteins at the BCSFB remains unknown. A transient appearance of specific junctions also occurs at the neuroepithelium during the first half of gestation [97, 126], but these so-called strap junctions are different in their organisation, in the orientation of their single strands that run perpendicular to the cell surface rather than in a belt-like manner around the circumference of the cell, and in their function. The molecular composition and regulation of strap junctions are likely unrelated to those of the choroidal epithelial cell tight junctions.

The epithelium of the choroid plexuses is a quiescent cell population. In the rat, virtually no mitosis was observed after P12 [20]. In humans mitoses stop after the 7th week of development [72]. Then they are only observed at the root of the plexus, a region which could account for the subsequent growth of the structure. These quiescent cells proliferate again after ischemia [79], intraventricular injection [21], or physical injury [7]. This proliferative response is important to keep in mind when performing plexectomy, a surgical procedure proposed to treat certain cases of hydrocephalus in humans. If the ablation of the plexus is only partial, then the proliferation of residual cells may lead to a restoration of the plexus. That is why it is absolutely necessary to practice in these cases a total ablation. 


\section{Neuroprotective functions of the blood-CSF barrier}

The choroidal epithelium, owing to its low transepithelial electric resistance, is considered a "leaky" epithelium. This is a feature shared by fluid-secreting epithelia which is related to a high but regulated ion permeation. Importantly, this apparent "leakiness" does not extend to organic compounds and large molecules. The choroidal epithelium forms an efficient barrier preventing deleterious compounds from entering or accumulating in the CSF. This relies on a restricted paracellular pathway, and on intracellular biochemical and enzymatic specificities, which in addition to CSF secretion, contribute to the neuroprotective functions of choroid plexuses.

\section{CSF secretion}

Owing to the "classical" buoyancy and drainage functions attributed to the CSF, its secretion can be considered as the first of the neuroprotective properties attributed to the choroid plexus. The historical demonstration that the choroid plexus is the major CSF secretion site in the brain was based on (1) the increased ventricular volume after foramen occlusion that was prevented by plexectomy, (2) the similar composition of choroid plexus-secreted fluid collected under oil in situ as compared to CSF, and (3) the existence of an arterio-venous positive concentration gradient for hematocrit and for polar tracer in choroidal blood (reviewed in [32]). Since these pioneering findings, the molecular mechanisms underlying CSF secretion by the choroidal epithelium have been largely deciphered.

The current model of CSF secretion is described in [47, 108]. A unidirectional active transcellular blood-to-CSF flux of $\mathrm{Na}^{+}, \mathrm{Cl}^{-}$, and $\mathrm{HCO}_{3}^{-}$creates an osmotic gradient followed by water movement. This active ionic flux results from the activity of carbonic anhydrase and $\mathrm{Na}^{+} /$ $\mathrm{K}^{+}$-ATPase, the latter enzyme being located on the apical membrane, a unique feature among all epithelia in the body. A large number of channels and transporters for monovalent inorganic ions, and aquaporin-1 participate in the secretory process. A number of issues relative to the mechanisms of CSF secretion remain, however, unresolved, among them the potential implication of the poreforming claudin-2 either in CSF-to-blood paracellular $\mathrm{K}^{+}$ transfer, or as a water channel ([108], and see below).

Dysfunction of choroidal CSF secretion could be part of the pathophysiological process leading to neurodegenerative diseases. Clinical observations showing that the choroid plexus-CSF system is altered in Alzheimer's disease support this hypothesis [134]. An alteration of choroid plexus vascular and epithelial morphology, a decrease in choroidal synthesis and transport capacity, and a decrease in CSF secretion is observed in aging, and is exacerbated in Alzheimer's disease [132, 134]. The CSF circulation plays a role in amyloid beta distribution and clearance from the brain [49]. An impaired drainage of the brain induced by a decreased CSF secretion may, therefore, favor amyloid deposition. In addition, dysfunction of amyloid beta choroidal clearance through one or several low density lipoprotein receptor-related proteins (LRPs) or a decreased secretion into the CSF of polypeptides such as transthyretin that bind and stabilize soluble amyloid beta [157] can sustain the pathology. The reason why the choroid plexuses are damaged and dysfunction in Alzheimer's disease is unclear, but may involve amyloid beta accumulation within the choroidal tissue. The hypothesis that a global choroid plexus-CSF system dysfunction favors neurodegeneration is supported by experimental work using Alzheimer's disease mouse models [53].

\section{Paracellular barrier properties of the choroid plexus epithelium}

As in all epithelia, the structural barrier properties of the choroidal epithelium are determined by the tight junctions. They form at the most apical part of the lateral space between neighboring cells (Fig. 1b). They control paracellular movements and guarantee the cell polarity by impeding the diffusion of transmembrane proteins between the apical and the basolateral membrane domains. Intercellular tight junctions are formed by a combination of transmembrane proteins, namely claudins and occludin, which interact with the F-actin cytoskeleton through various scaffold cytoplasmic proteins [172]. Claudins, which are actually responsible for controlling the paracellular permeability, are of two types. Barrier forming claudins seal the paracellular pathway, and channel forming claudins allow the charge- and size selective passage of electrolytes and small solutes. The claudin repertoire expressed in a given barrier tissue and the way these proteins dimerize between adjacent cells, confer to this barrier its intrinsic properties in term of permselectivity and impermeability. A thorough analysis of claudin transcripts in rat choroid plexus highlighted three major claudins expressed at high levels, Cldn-1, -2 and -3 [74]. The distribution of these proteins is restricted to the apical tight junctions in the choroidal epithelial cells. Claudin-1 and -3 are typical of "tight" epithelia, and are impermeable to ions, water, and larger solutes [121]. Claudin-2 is typical of "leaky" epithelia with secretory functions like the kidney proximal tubule. It forms a paracellular channel selective for small cations $\left(\mathrm{K}^{+}, \mathrm{Na}^{+}\right)$and is also the only channel forming claudin that cotransports water [120]. It is sufficient to induce a low transepithelial resistance in the highly resistant 
MDCK C7 cell line, without affecting the paracellular diffusion of non-charged solutes. The expression of claudin-2 in the BCSFB brings some understanding to the fact that electrophysiologists classified the choroid plexus in the "leaky" epithelium category. The lack of claudin- 2 expression in the BBB presumably explains the large difference in electrical resistances measured in the two interfaces. The paracellular movement of water through the channel forming claudin-2 in choroidal cells may also explain, at least partially, why knocking out aquaporin-1 in mouse decreased CSF secretion only by $35 \%$ [103]. The basis for having both a transcellular water pathway through aquaporin and a paracellular water pathway through claudin- 2 could be to provide an energy saving mechanism, as shown in the renal proximal tubule [106].

Claudin expression is developmentally regulated, which may reflect physiological adaptation to microenviromental changes during brain development. Similar data concerning claudin- $1,-2$, and -3 ontogenic regulation were reported for rat, mouse, and human choroid plexus [74, 146]. Importantly, the barrier forming claudin-1 and -3 appear very rapidly after the choroid plexuses start to bulge in the ventricles and differentiate (Fig. 4a). A functional correlate has been established by permeability studies at early embryonic stages [80]. Claudin-2 expression appears to follow the developmental increase in CSF secretion capacity. Besides these three major claudins, a number of other barrier forming and channel forming claudins are expressed in the choroid plexus [74], and some of them, such as claudin-9 and -19 have been immunodetected in apical junctions of the rat choroidal epithelium. Claudin-5, the prototypical BBB claudin, distributes at the junctions in large penetrating stromal vessels in rat and mouse and possibly in some smaller vessels [74, 82, 146]. Its expression in the choroidal epithelium was not detected in rat and mouse, but was recently described in human neonates [164]. Claudin-11 was immunodetected at epithelial junctions in mouse choroid plexus [166]. These data need to be confirmed because the antibody used was later found to cross-react with claudin-10 [99], also expressed at the choroid plexus [74]. The peculiar parallel organization of tight junction strands in the choroidal epithelial barrier, initially attributed to claudin-11 [166], could alternatively be related to the choroidal expression of claudin-19, which also forms tight junctions with parallel strands in Schwann cells of the peripheral nervous system [94]. The permeability at tricellular junctions, which form at the meeting point of three neighboring cells, is regulated by tricellulin. This transmembrane protein mainly restricts the paracellular movement of large molecules. It has little effect on ion diffusion, given the very limited area of exchange provided by the tricellular junctions in comparison to the length of intercellular lateral tight junctions, at which ion control is effective. Tricellulin has been detected at tricellular junctions in the mouse choroidal epithelium [61]. A new partner critical for the apical formation of tight junctions in choroid plexus is the protein Alix, involved in endocytosis and endosome sorting processes, and expressed at high levels in the BCSFB. Alix has a critical role in promoting the formation of apical tight junction complexes. Absence of Alix leads to a total disorganization of the choroid plexus tight junctions and to hydrocephalus [15].

In peripheral organs, claudins as well as tricellulin are regulated by inflammation, oxidative stress, or ischemia/ hypoxia. A loss of claudin-1, -2 or -3 was observed in the choroidal epithelium in animals with experimental autoimmune encephalomyelitis or in multiple sclerosis patients $[71,166]$. The functional consequences of these changes on the BCSFB permeability to paracellular markers have not been explored. By contrast, a functional loss of the choroidal barrier properties, assessed by measuring inulin permeation was observed during ischemia/reperfusion in the rat [42]. It suggests that tight junctions are altered by the injury, but alterations in claudin expression and localization were not examined. Tricellulin may be a target in lead-induced cerebral toxicity. The metal accumulates in the choroid plexus in humans and in animal models, leading to a dysregulation of TTR production and thyroid hormone transport. It may also affect tricellulin expression and functionality by inducing the level of the regulating microRNA mir203, as suggested by in vitro studies [152].

\section{Enzyme- and transporter-mediated barrier properties of the choroidal epithelium}

The BCSFB harbors a versatile machinery that protects the brain and CSF against a wide spectrum of xeno- and endobiotics. This machinery uses efflux systems, which belong to the ATP-binding cassette (ABC) transporter family and distinctive solute carrier (SLC) subfamilies, and are selectively distributed between the apical and basolateral membrane domains of the choroidal epithelial cells. These transporters either restrict the penetration of compounds into the CNS or favor the clearance of potentially deleterious metabolites from the CSF. The neuroprotective machinery also comprises a panel of metabolizing enzymes, which generally inactivate their substrates and work in concert with efflux transporters to prevent the intracerebral accumulation of noxious molecules (Fig. 4b).

Specifically, the choroidal energy-dependent ABC transporters $\mathrm{ABCC} 1$ and $\mathrm{ABCC} 4$, located at the blood facing membrane (basolateral side) can extrude a wide range of structurally unrelated lipid soluble compounds following their passive diffusion within the epithelial cells. These compounds include various environmental pollutants and drugs from diverse therapeutical classes (anti-tumoral, anti-epileptic, anti-infectious, anti-depressant, immunosuppressant 


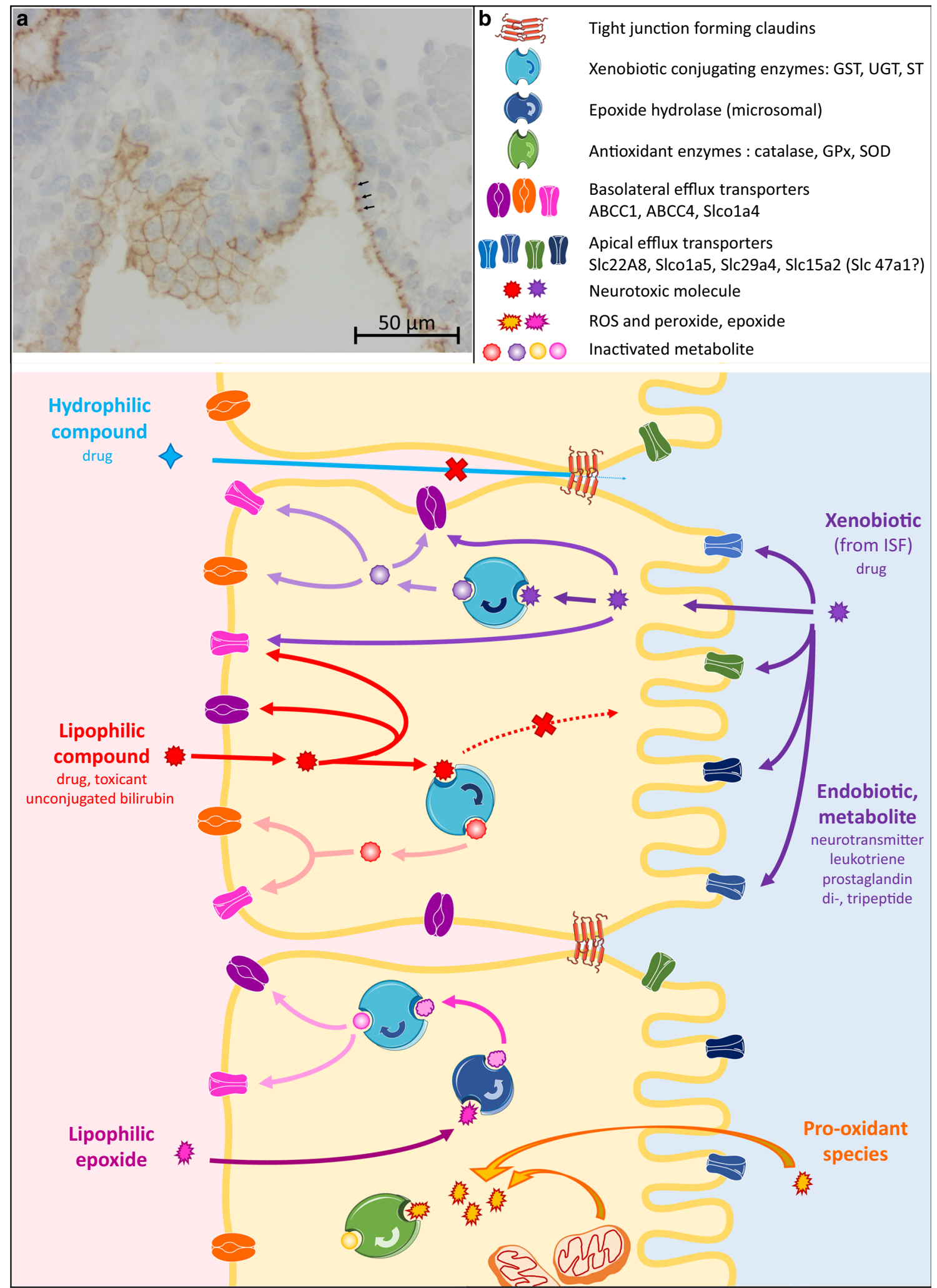

(reviewed in [149]). The transporter ABCC1 may also restrict the penetration of plasma unconjugated bilirubin into CSF [45], and thus contribute to protect the brain in case of moderate transient hyperbilirubinemia, such as occurring in neonatal jaundice. The expression in the choroidal epithelium of $\mathrm{ABCB} 1$ and $\mathrm{ABCG} 2$, two hallmark transporters of the $\mathrm{BBB}$, is debated [44, 91, 119]. Given their supposedly apical/subapical localization, these proteins would 
4Fig. 4 Molecular determinants of the neuroprotective functions in the blood-CSF barrier. a The tight junction protein claudin-1 seals the paracellular pathway of the choroidal epithelium from an early embryonic developmental age. Claudin-1 immunoreactivity is continuous and confined to the apical part of intercellular junctions (arrows). Staining of the choroid plexus of the fourth ventricle in a human brain obtained at 10 weeks of development, as described in Kratzer, 2012. Courtesy of Alexandre Vasiljevic. b The BCSFB harbors a versatile machinery coupling metabolizing enzymes with plasma membrane efflux transporters to limit the blood-to-CSF transfer and favor the cerebral clearance of exogenous and endogenous noxious molecules. These efflux transport systems have different but broad and partially overlapping substrate specificities, distribute at both membranes in a polarized pattern, and can work in concert to generate a high level of neuroprotection. They also clear intracellularly produced metabolites formed by the panel of detoxifying conjugating enzymes UDP-glucuronosyltransferases (UGT), glutathione$S$-transferases (GST), and sulfotransferases (ST). Further protection is provided by antioxidant enzymes (catalase, superoxide dismutase SOD, glutathione peroxidases GPx) and by epoxide hydrolase, which inactivate reactive oxygen species and reactive pro-oxidant epoxides, respectively

accelerate the transfer of deleterious compounds into the $\mathrm{CSF}$, and further studies are awaited to clarify these inconsistencies. Multispecific SLC transporters are located at the apical membrane, with the exception of Slcola4 present in the basolateral domain. Slco1a5 (in rodent) and SLC22A8 at the CSF-facing membrane function as inwardly directed transporters and mediate the cellular uptake of CSF-borne molecules. They transport various drugs such as antiviral, antibiotic, and non-steroidal anti-inflammatory agents. They also transport endogenously produced hormones (estrone sulfate, dehydroepiandrosterone sulfate) and inflammatory modulators (prostaglandins, leukotrienes) (reviewed in [149]). More recently, other carriers of the SLC family, relevant to efflux processes, have been identified in the BCSFB, such as the multidrug and toxin extruder SLC47A1, or else the organic cation transporter SLC29A4 [159, 160]. This last efflux system transports various monoamine neurotransmitters, serotonin, dopamine, and histamine, as well as 1-methyl-4-phenylpyridinium-like neurotoxins. It is located at the apical membrane of the choroidal epithelial cells. By removing monoamines from CSF, SLC29A4 contributes to terminate central signaling of neurotransmitters, and in the case of histamine, the transporter could play a key role in sleep-wake regulation [160]. Di-and tripeptides are specifically eliminated from the CNS across the BCSFB by SLC15A2 located at the apical membrane [139]. Speciesdependent variations in the identity of certain efflux transporters have been highlighted by a recent proteomic study on rodent and human choroid plexus. This study suggests that there may be differences in the abundance of some transporters, SLC15A2 or SLC47A1 for example, between rat and human choroid plexus [159]. The human data, based on the analysis of a unique sample collected from an aged individual need to be validated, and the functional consequences of species differences remain to be delineated as the efflux systems have usually large and partially overlapping substrate specificities.

To complement this specific set of efflux transporters, the choroid plexuses express a large panel of metabolizing enzymes, which transform endogenous molecules, drugs, or toxicants into water-soluble and usually inactive metabolites. The BCSFB likely represents the major site of xenobiotic metabolism in the brain [149]. High specific activities have been measured for epoxide hydrolase and various conjugating enzymes, which catalyze the addition of hydrophilic moieties such as glucuronic acid, glutathione or sulfate. Growing evidence shows that these conjugating enzymes coupled to the ABC or SLC efflux transporters located at the basolateral membrane of choroidal epithelial cells form an efficient metabolic barrier, which limits the penetration of xenobiotic substrates into the CSF [50, 148]. High glutathione- $S$-transferase and sulfotransferase activities, as well as high ABCC expression levels were measured in human choroid plexuses $[44,50,116]$, suggesting that similar barrier mechanisms occur in human. Such an enzymatic barrier process also exists for endogenous molecules, like monoamine neurotransmitters, which intracerebral concentration needs to be strictly controlled. The choroid plexus has a high monoamine oxidase B activity, which prevents the passage of circulating dopamine and may potentially assist in the breakdown of amines cleared from the CSF [81]. It is tempting to extend this mechanism to another enzyme, the 15-hydroxyprostaglandin dehydrogenase specifically expressed in the choroid plexus, especially in early postnatal life, and mediating prostaglandin E2 catabolism [2]. Finally, several antioxidant enzymes, catalase, glutathione peroxidases, and superoxide dismutase are highly active in the choroid plexus, providing a protective mechanism against reactive oxygen species and organic peroxides [158].

These choroidal efflux transporters and metabolizing enzymes are for a large majority expressed at already substantial levels during the perinatal period, while the BBB is less mature with respect to neuroprotection. This is in line with an early maturation of the choroid plexuses during development and suggests that the BCSFB plays a predominant role in brain protection in the neonate and young infant [73, 150].

The transport and metabolic barrier mechanisms can be deregulated in different CNS diseases such as ischemia, inflammation, and infection, with potential consequences on the resolution of these pathologies. The BCSFB is involved in the continuous removal of prostaglandin E2 from the CSF, keeping low the intracerebral levels of this proinflammatory mediator [156]. A downregulation of prostaglandin E2 efflux transporters occurs in the models of bacterial meningitis and viral infection, and may exacerbate the effects of neuroinflammation [57, 67]. Chronic moderate hyperbilirubinemia 
depresses $\mathrm{ABCC} 1$ levels, which may actually potentiate bilirubin neurotoxicity [45]. Of importance, cytoprotective transporters and enzymes are under the transcriptional regulation of nuclear factors, which are expressed in the choroid plexuses [73]. The nuclear factor erythroid 2-related factor 2 pathway, in particular, represents an attractive target to protect the BCSFB and induce its antioxidant capacities in neurological disorders associated with oxidative stress [168].

\section{The choroid plexus: dynamic supplier of regulatory factors for neural stem cells and brain function}

The choroid plexuses have important roles in brain homeostasis, including the production of bulk CSF. They have recently begun to receive more attention as, in addition to being a barrier and an entry pathway for a large variety of molecules into the brain, they also actively synthesize and secrete diverse signalling factors. Indeed, they are a key regulator of adult neural stem cell niches. A less-appreciated facet of the choroid plexuses is that they act as a sensor, integrating and responding to physiological signals from the circulation, nervous system and immune system. Choroid plexus epithelial cells express an array of growth factor and hormone receptors, allowing them to sense and respond to local changes in the niche as well as to different physiological signals by changing their secretome dynamically. The choroid plexuses are, therefore, well positioned to be key components of metabolic and neuroendocrine regulation, potentially having a long-range effect on global physiology and pathological states.

To understand the contribution of the choroid plexuses as a source of active factors in the brain, it is important to keep in mind their unique structural features, namely an outer layer of specialized epithelial cells that surround a highly vascularized inner stroma. The epithelial cells, interconnected by tight junctions, form a polarized epithelial barrier exposed to brain-derived signals from the apical side, via the CSF, and to peripheral signals from the basal side, via the circulation. The stroma contains diverse cell types, including immune cells, microglia, fibroblasts, and macrophages, all of which can be a source of factors.

\section{Source and regulated entry route of factors into the brain}

A central role of the choroid plexuses is the production of bulk CSF. Importantly the choroid plexuses also contribute to the CSF composition by serving as an entry route for blood-derived factors into the brain across the BCSFB, and by actively secreting a wide variety of factors.
Molecules are transported in a highly regulated manner across the choroid plexuses, via facilitated or active transport or by transcytosis of ligands bound to receptors. These include inorganic ions, for maintaining ionic balance under homeostasis, small organic compounds, essential metabolic nutrients (glucose and amino acids), hormones and micronutrients (vitamin C), polypeptides and proteins [149].

The choroid plexus itself is an important source of diverse molecules including active signaling, trophic and guidance molecules. Bioactive polypeptides, cytokines, extracellular matrix, carriers, growth factors, and hormones are synthesized and released from the choroid plexuses into the CSF. These factors can reach distal areas of the brain via bulk flow of the CSF and can act in both an autocrine and paracrine manner [63, 137]. In addition to diffusible factors, exosomes containing signaling factors and non-coding (nc) RNAs, such as long ncRNAs and miRNAs, are present in the CSF [11] and can be choroid plexus-derived [6, 55]. Finally, the choroid plexuses also contain a large array of enzymes and act as an enzymatic or metabolic barrier, by modulating the activity and availability of neurotransmitters, peptides, growth factors, hormones, drugs and xenobiotics. Interestingly, the repertoire of factors secreted by choroid plexuses is different in each brain ventricle [85], suggesting that each choroid plexus may act as a local center for the secretion and processing of distinct pools of active factors.

\section{The choroid plexus secretome: a dynamic regulator of brain development and adult neural stem cells}

In addition to its key role in brain homeostasis, recent work has shown that the CSF and choroid plexus-derived factors are important, stage-specific regulators of brain developmental processes and adult neural stem niches. Importantly, the CSF composition and protein concentration change throughout development and in the adult, as well as in aging, and can, therefore, exert distinct effects at different stages during development and in the adult (Fig. 5a, b).

\section{Embryonic and postnatal development}

During embryonic brain development, the earliest neural progenitors are located adjacent to the ventricles. They must expand rapidly in a short period of time, and then, either directly or via intermediate progenitors, generate neurons and later, glia. Both hydrostatic pressure of the CSF and its chemical composition are important during brain development. Decreasing hydrostatic pressure results in smaller brain ventricles, and smaller and disorganized neural tissue [63]. Factors within the embryonic CSF, including sonic hedgehog and choroid plexus-derived insulin-like growth factor 2, promote the proliferation of neural progenitors [59, $78,90,170]$. The CSF effect is optimal when age-matched 
a

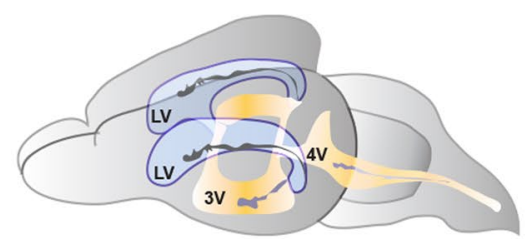

b

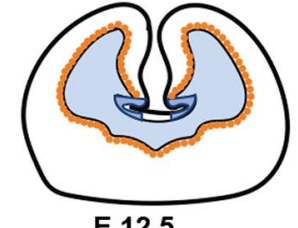

E 12.5

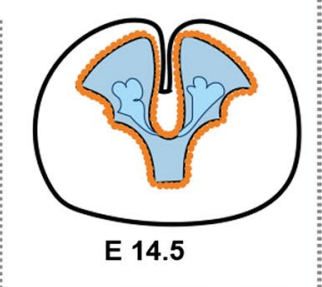

CSF

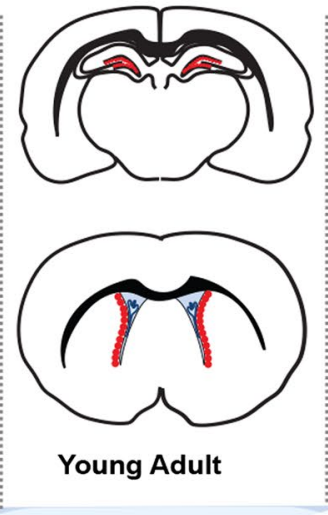

CSF

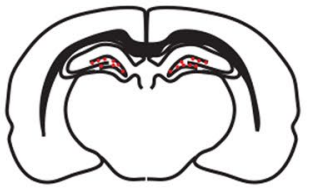

SGZ

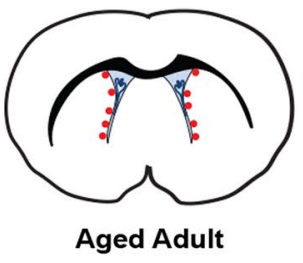

CSF

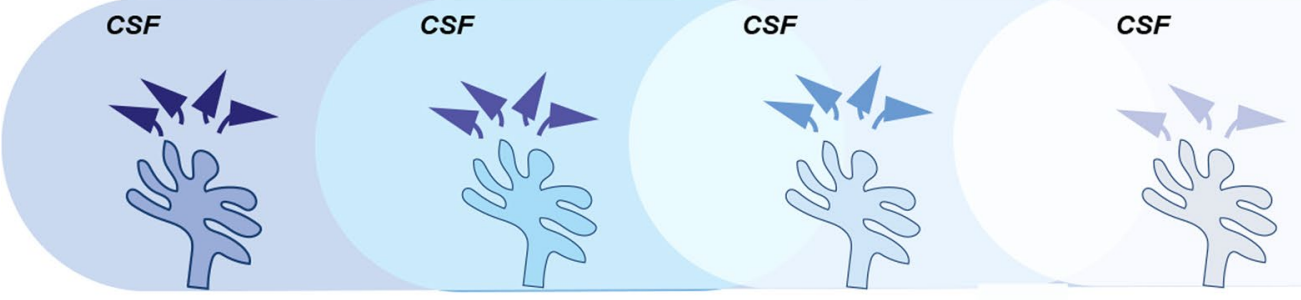

C

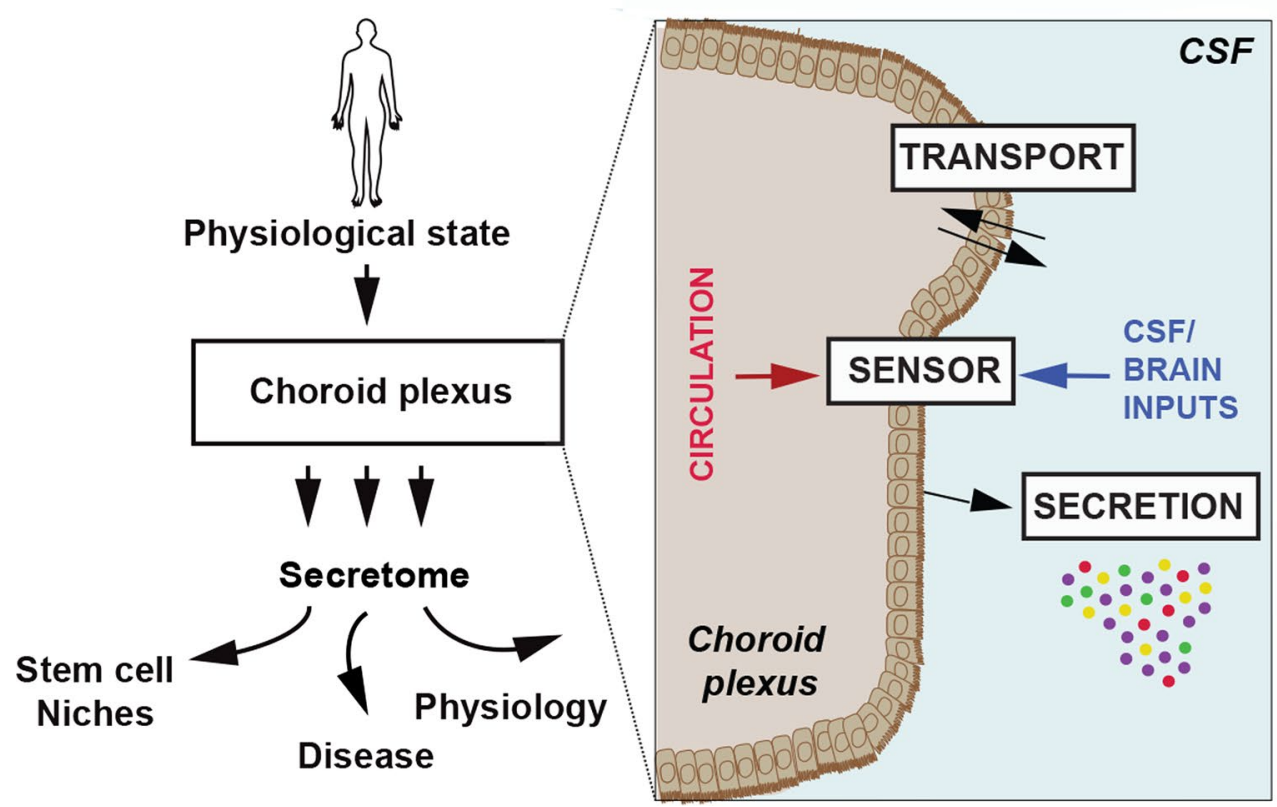

Fig. 5 The choroid plexus regulates neural stem cells and brain function. a Schema of adult mouse brain showing ventricular system and the choroid plexuses in each ventricle: $\mathrm{LV}$, lateral ventricle, $3 \mathrm{~V}$, third ventricle, $4 \mathrm{~V}$, fourth ventricle). b Schemas showing coronal sections of the mouse brain at different stages of embryonic development and in the adult. Orange dots show location of neural progenitors in the ventricular zone of the developing brain (E12.5 and E14.5). Red dots show ventricular-subventricular zone (V-SVZ) and subgranular zone (SGZ) adult neural stem cell niches. With aging, proliferation and neurogenesis decrease in the adult brain. Changes in the colour

CSF and tissue are combined, highlighting the dynamic nature of both the choroid plexus/CSF axis and of the intrinsic state of the responding cells $[18,78]$. Factors in the blood of the choroid plexus and CSF below represent changes in the choroid plexus secretome and CSF composition from development through aging. c Schema showing a model of the choroid plexus as a hub, which integrates signals from the circulation and the brain that reflect the physiological state. In addition to being a source of factors via transport and synthesis, the choroid plexus is a sensor of different states. By dynamically altering its secretome in response to input signals, the choroid plexus modulates stem cell behaviour in adult neural stem cell niches, can affect physiology and contribute to pathology

are also transported across the BCSFB. One example is folate, which is transcytosed and released in exosomes into the CSF to reach the brain parenchyma [55]. This choroidal 
function is key to normal brain development, as inherited or acquired choroidal folate transport defects induce cerebral folate deficiency that translate into severe childhood neurodegenerative diseases [54, 142], and may be a main contributor to the encephalopathy associated with the Kearns Sayre syndrome [141]. Due to the flow of the CSF through the ventricular system, factors can exert long-range, as well as regionally distinct effects, depending on local concentration gradients of individual factors and the repertoire of receptors and modulators expressed by the responding cells [64].

Another emerging role for choroid plexus-derived factors is in modulating cerebral cortex plasticity during postnatal stages. Choroid plexus-derived Otx2 is widely distributed throughout the brain and is taken up by parvalbumin ${ }^{+}$neurons, where it regulates the maturation of neural circuitry and critical periods of plasticity in the visual cortex. Blocking release of Otx 2 from the choroid plexus in the adult reopens binocular plasticity in the visual cortex [140]. Thus, choroid plexus-derived factors may globally affect neural circuit formation, activity and plasticity during critical periods, as well as in the adult brain.

\section{Adult}

In the adult mammalian brain, there are two principal neural stem cell niches, the ventricular-subventricular zone (V-SVZ) adjacent to the lateral ventricles, and the subgranular zone (SGZ) of the hippocampal formation. Niche signals are key regulators of adult neural stem cell behaviour. The lateral ventricle choroid plexus (LVCP) is in close proximity to the adult V-SVZ, but affects both adult germinal regions.

Stem cells in the adult V-SVZ exist in quiescent and activated (dividing) states [23], and give rise to neurons, as well as to glia. Both the levels of adult neurogenesis, and the destination of newly generated neurons exhibit species-specific differences [17, 104]. However, stem cells across phylogeny share a common glial identity and localization. V-SVZ stem cells directly contact the ventricle, and are bathed by the CSF. Recent work in mice has begun to identify choroid plexus-derived factors that regulate adult neural stem cell proliferation and differentiation. Choroid plexus-derived interleukin $1 \beta$ and neurotrophin 3 in the CSF promote neural stem cell quiescence [35, 69]. Importantly, the LVCP is emerging as a key niche compartment of the adult V-SVZ, which not only affects stem cells, but also each stage of the lineage [137]. In addition to modulating stem cell quiescence, the LVCP secretome promotes stem cell recruitment, proliferation of their progeny and differentiation into neuronal and glial lineages [137]. The choroid plexus also secretes migratory cues for newly generated neurons [127]. In the V-SVZ, stem cells have a regional identity and give rise to different subtypes of neurons and glia [17]. The diverse array of factors secreted by the LVCP may differentially regulate distinct stem cell pools depending on the combination of receptors they express. Importantly, the effect of the LVCP secretome changes during aging, selectively affecting the behaviour of activated neural stem cells [137]. Young LVCP secreted factors can partially reverse the functional behaviour of aged V-SVZ adult stem cells, and vice versa, highlighting the dynamic nature of the LVCP secretome and consequently, its effects on adult neural stem cells.

The LVCP also acts, via long-range signaling, on the adult hippocampus. During aging, a Type I interferon transcriptional program is increased specifically in the LVCP, due to CSF-derived signals but not factors in the circulation [9]. Blocking Type I interferon signaling in the CSF of aged mice partially rescued cognitive defects and hippocampal neurogenesis, and re-activated Type II interferon choroid plexus activity, which is high in young adults, but lost in aging [9]. The LVCP, therefore, is an important regulator of both adult neural stem cell niches. In the future, it will be important to identify choroid plexus-derived factors in humans and define their effects on adult neural stem cells.

\section{Sensor and modulator of physiological states in the adult}

With its position at the interface between the blood and the CSF, the choroid plexuses are uniquely placed to sense physiological states and integrate local and long-range signals from the circulation, nervous system, and immune system $[9,88]$ (Fig. 5c). Indeed, the choroid plexus transcriptome, proteome, and secretome are dynamic and rapidly change in response to external cues, such as inflammation [89, 155]. Choroid plexus epithelial cells have many villi, providing a large surface area for detection of signals in the CSF. They also have multiple primary cilia, which can sense and transduce signals from the brain environment. Epithelial cells also express a large repertoire of receptors for diverse molecules, including neurotransmitters, hormones, cytokines, growth factors, and bacterial toxins. As such, they can sense signals in both the CSF and blood, both of which can differentially affect the transcriptome and secretome of choroid plexus epithelial cells [9]. How other choroid plexus cell types respond to external inputs from the circulatory, autonomic, and immune systems and in turn change their secretome is still unknown.

Many physiological processes in mammals are influenced by both circadian and seasonal rhythms. The CSF composition exhibits circadian and seasonal fluctuations, which are at least in part due to dynamic changes in the choroid plexus $[112,138]$. As outlined above, the choroid plexuses can modulate physiologiocal states, such as aging $[9,137]$. The choroid plexuses are also targets for sex hormones, and can, therefore, elicit gender-specific effects [124] with 
important implications for physiology. The choroid plexus, via its transport function and secretory activity modulates neuroendocrine processes [138], providing a path to deliver physiological signals, such as leptin and thyroid hormone (T4), from peripheral blood to different brain areas including the hypothalamus and brain parenchyma via the CSF. It also directly synthesizes hormones and neuropeptides (including growth hormone, vasopressin, and insulin-like growth factor 1), as well as peptide processing enzymes (including for proopiomelanocortin and insulin) and modifying enzymes (such as prostaglandin D2 synthase), which can affect adult V-SVZ neural stem cells [105, 137], and impact global physiological states.

In sum, the choroid plexuses are emerging as a key sensor and modulator of physiological states by acting as a hub that translates physiological changes into molecular signals directly affecting adult neural stem cell behaviour, neurogenesis and global physiology (Fig. 5c). As such, changes in choroid plexus function can potentially lead to a variety of pathological conditions.

\section{Neuroimmune interactions at the blood-cerebrospinal fluid barrier}

As cells from the adaptive immune system can be detected in the CSF but not in the CNS parenchyma in healthy individuals, the choroid plexuses and arachnoid which form the interfaces between the blood and CSF have recently moved into the focus of attention as the neuroimmune gateways regulating CNS immunosurveillance [41]. At the choroid plexuses, several cell types participate to immunosurveillance and neuroinflammation, and the choroidal responses to inflammatory stimuli are multiple.

\section{Neuroimmune function of the choroid plexuses in health}

The CNS parenchyma of healthy individuals harbors yolk sac-derived long-lived microglial cells [109] but is devoid of immune cells from the adaptive immune system such as $\mathrm{T}$ cells or B cells. T cell mediated CNS immune surveillance is rather strictly limited to the CSF-filled ventricles and subarachnoid spaces. This is supported by the observation that in healthy individuals 150,000-750,000 immune cells are present in the CSF [68] and they are equally distributed between the ventricular and lumbar CSF [110]. Other sterile bodily fluids, e.g. synovial or pleural fluid contain 10-100-fold more immune cells than CSF, but the majority is composed of innate immune cells rather than $\mathrm{T}$ cells or B cells. In contrast, the few immune cells circulating in the $\mathrm{CSF}$ are mostly $\mathrm{T}$ cells with a ratio of $\mathrm{CD} 4^{+} \mathrm{T}$ cells to $\mathrm{CD} 8^{+} \mathrm{T}$ cells of about 3.5 to 1 (summarized in [113]). The population of T cells found in the CSF of the ventricles and subarachnoid space contains mostly memory $\mathrm{T}$ cells that have characteristics of central memory $T$ cells $\left(\mathrm{T}_{\mathrm{CM}}\right.$ cells) and effector memory $\mathrm{T}$ cells ( $\mathrm{T}_{\mathrm{EM}}$ cells) $[33,123]$. Animal models have provided additional evidence for the presence of yet another subset of memory T cells in the CNS that do not recirculate but rather persist in the CSF-drained spaces after previous infections [165]. These $\mathrm{T}$ cells are referred to as $\mathrm{CD}_{103}{ }^{+}$tissue resident memory $\mathrm{T}$ cells ( $\mathrm{T}_{\mathrm{RM}}$ cells) and provide an organ-autonomous defence system for the CNS for future infections [145].

Considering the restricted localization of these memory $\mathrm{T}$ cell subsets in the CSF compartment within the CNS it appears highly likely that the cells forming interfaces between the blood and the CSF play an important role in regulating T cell entry into the CNS. While there is no direct evidence for immune cell entry from the dura mater across the arachnoid membrane into the subarachnoid space, accumulating evidence points to immune cell entry into the CNS ventricles via the choroid plexuses [36, 101, 114, 129]. A key function of both the arachnoid and the choroid plexuses in regulating CNS immunity is, however, suggested by the high amount of MHC class II expressing myeloid cells found strategically positioned on either side of the barriers. On the blood facing side of the arachnoid membrane, the dura mater harbors a high number of macrophages and dendritic cells [24]. On the CSF side of the arachnoid the subarachnoid space is home to numerous tissue resident MHC class II expressing macrophages, some of them even in tight contact with the arachnoid barrier and perforating the arachnoid lining at the CSF side with their processes [13]. Subarachnoid macrophages exert scavenger functions and present CNS antigens to T cells entering this CSF space as shown by elegant in vivo live cell imaging studies [ 8 , $84,107]$. Combined parabiosis and fate-mapping studies in transgenic mice provided recent evidence that subarachnoid macrophages arise from hematopoietic precursors during embryonic development and establish a stable long-lived population of innate immune cells in this compartment [52]. These myeloid cells share this origin with the Kolmer's epiplexus cells that reside on the apical-i.e. CSF-side of the choroid plexus epithelium, and have first been described by Kolmer [70]. As the choroid plexuses are located in strategically important places in each ventricle, namely the narrow foraminae through which the CSF passes from the lateral ventricles to the third ventricle and from the fourth ventricle to the cisterna magna and to basal cisterns of the brain, it is tempting to speculate that Kolmer's epiplexus cells serve similar functions as the subarachnoid macrophages as they are in a prime position to scavenge the CSF for antigens (Fig. 6). The unique characteristics and especially the previously unrecognized longevity of subarachnoid macrophages and Kolmer's epiplexus cells may contribute to shaping CNS 

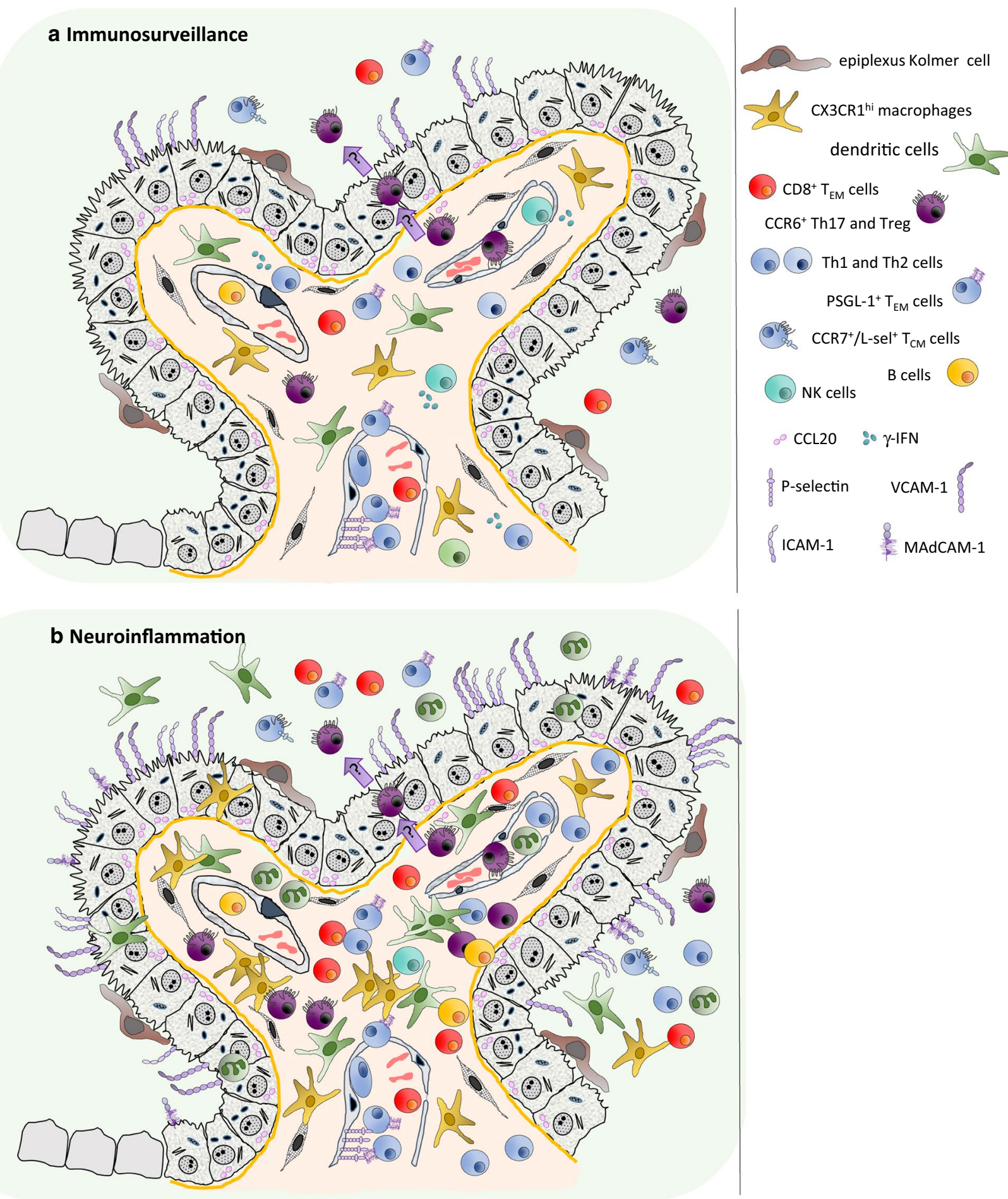

immune surveillance in a unique fashion as these antigenpresenting cells do not readily leave the CSF space towards the peripheral draining lymph nodes.

An important immunological function of the choroid plexus in its entity has long been proposed $[36,101,144]$ and has been underscored by numerous descriptions of the high numbers of MHC class II expressing bone marrow-derived macrophages and dendritic cells [101, 133] residing in the highly vascularized choroid plexus stroma that is exposed to blood component due to the lack of an endothelial barrier (Fig. 6). As discussed above these myeloid cells are distinct from the myeloid subsets in the CSF spaces. Interestingly, choroid plexus stroma dendritic cells can also reside between choroid plexus epithelial cells and extend their dendrites 
4Fig. 6 Schematic overview of the neuroimmune environment in the choroid plexuses during health and neuroinflammation. a Immunosurveillance. The choroid plexus stroma is irrigated by fenestrated microvessels lacking a BBB and allowing free diffusion of bloodborne molecules into the stroma. The epithelial cells of the choroid plexus surround the entire choroid plexus stroma and form the BCSFB which controls transport of molecules and immune cells across this barrier. During health (immunosurveillance) IL-10 producing dendritic cells and $\mathrm{CX} 3 \mathrm{CR} 1^{\mathrm{hi}}$ (M2 like) macrophages are found in the choroid plexus stroma. Furthermore, effector memory $\mathrm{T}$ cells can reside in the choroid plexus stroma and may extravasate from choroid plexus microvessels in a P-selectin/PSGL-1 dependent manner. Consitutive expression of the chemokine CCL20 in choroid plexus epithelial cells may guide CCR6 ${ }^{+}$Th17 and Treg cells into the CNS via the choroid plexuses. Presence of effector/memory $\mathrm{T}$ cells $\left(\mathrm{T}_{\mathrm{EM}}\right)$ in the CSF of healthy individuals suggests that these $\mathrm{T}$ cells enter the ventricular space via the choroid plexuses and may become central memory $\mathrm{T}$ cells $\left(\mathrm{T}_{\mathrm{CM}}\right)$ if not further activated in the CNS. At their apical side choroid plexus epithelial cells express the adhesion molecules ICAM-1 and VCAM-1 and harbor epiplexus Kolmer cells which belong to the myeloid cell lineage. b Neuroinflammation. During neuroinflammation innate and adaptive immune cells accumulate in the choroid plexus stroma and expression of epithelial ICAM-1 and VCAM-1 is upregulated, while expression of MAdCAM-1 is de novo induced. Innate immune cells are detected between the epithelial cells suggesting they cross the BCSFB. In the CSF increased numbers of immune cells can be detected. Symbols for immune cells and immunomodulatory molecules depicted in the schemes are explained in a

into the CSF filled ventricles [133], where they might take up CSF antigens for presentation to $\mathrm{T}$ cells in the choroid plexus stroma [101].

This is supported by the observation that $\mathrm{T}$ cells found in the choroid plexus stroma are enriched for CNS-specific effector/memory $\mathrm{CD}^{+}{ }^{+} \mathrm{T}$ cells [10] (Fig. 6). In the absence of neuroinflammation local activation of CNS-specific Th1 and Th 2 cells induces expression of the Th1 and Th2 signature cytokines, IFN- $\gamma$ and IL-4, which may maintain expression of trafficking molecules at the choroid plexus allowing for limited $T$ cell trafficking into the ventricles $[10,75]$. The choroidal endothelium, fenestrated and thus permissive to large molecules, does not display a BBB phenotype. Yet $T$ cells need to adhere and get through this endothelium to reach the choroidal stroma, and then the CSF across the epithelium. The mechanisms allowing this two-step migration process remains to be fully elucidated (Fig. 6).

At the same time choroid plexus dendritic cells can promote immunological $\mathrm{T}$ cell silencing [19] via secretion of IL-10 [133]. The immunoregulatory function of the choroid plexuses has further been supported by local expression of complement proteins and their regulators (summarized in [41]). Overall, in absence of neuroinflammation the choroid plexuses thus seem to play an underestimated role in maintaining CNS immunity and may be critical structures ensuring local activation of CNS-specific T cells and their controlled subsequent migration across the choroidal epithelium allowing them to enter into the CSF niches of the CNS.
The laboratory of Michal Schwartz has coined the term "protective autoimmunity" [96] to develop this concept even further by including their experimental observations supporting the notion that presence of CNS-specific T cells in the CSF contributes to life-long protection, maintenance and repair of the CNS. This concept suggests that suboptimal trafficking of immune cells into the CNS via the choroid plexuses might be an underlying mechanism shared in the pathophysiology of neurodegenerative conditions [130]. The proposed underlying mechanism is a balance between type I and type II interferon signaling which may regulate immune cell entry into the CNS with important consequences for CNS physiology or pathology [34].

\section{Neuroimmune function of the choroid plexuses in neurological disorders}

In neurological disorders as different as brain trauma [155], perinatal inflammation triggered by bacterial components [151], and experimental autoimmune encephalomyelitis (EAE) [41], the balanced cytokine and chemokine milieu within the choroid plexuses changes rapidly and may thus directly contribute to altered immune cell activation and their subsequent trafficking across the inflamed BCSFB into the CNS. Increased numbers of T cells and B cells are found in the CSF of patients with CNS infections or multiple sclerosis $[3,16]$.

A large body of our current knowledge on immune cell trafficking to the CNS is derived from studies in EAE, an animal model for multiple sclerosis. In EAE, activated autoaggressive $\mathrm{CD}^{+}{ }^{+} \mathrm{T}$ cells enter the CNS where they cause neuroinflammation, demyelination and BBB breakdown, which resembles the pathological signs observed in multiple sclerosis. EAE is accompanied by significant morphological changes of the choroid plexuses, which are characterized by loss of apical microvilli and mitochondrial alterations in the choroid plexus epithelium and appearance of a higher number of electron dense, i.e. "dark cells" in the epithelium [41].

In EAE, inflammation in the choroid plexuses and CSF precedes the formation of brain and spinal cord inflammatory infiltrates and the development of demyelinating white matter lesions [14, 129]. Granulocytes [41] and myeloid cells taking up circulating very small superparamagnetic iron oxide particles (VSOP) accumulate in the stroma of the choroid plexuses prior to the onset of EAE $[41,93]$. Interestingly, VSOP accumulation is undetectable in the non-inflamed CNS suggesting that the resident myeloid cells in the choroid plexus stroma require an inflammatory stimulus to actively phagocytose VSOPs. Increased numbers of MHC class II expressing myeloid cells have also been observed in the choroid plexuses from patients with multiple sclerosis or viral encephalitis but not in patients with amyotrophic lateral sclerosis 
Fig. 7 Ultrastructural localization of ICAM-1 and VCAM-1 by immunocytochemistry on ultrathin frozen sections of the choroid plexus from a SJL/N mouse suffering from EAE. Typical epithelial apical microvilli are shown. Gold particles are found at the microvilli but not the cytoplasm of the plexus epithelial cells stained with antibodies against ICAM-1 and VCAM-1. No gold particles are detected in sections incubated with isotype control antibody. For details see [167]

[162]. This underscores a neuroimmune implication for the choroid plexus in immune system-mediated neuroinflammatory disorders rather than in CNS disorders in which primary events are initiated in the CNS. This is further supported by the observation that the choroid plexuses of patients with multiple sclerosis and viral encephalitis but not with amyotrophic lateral sclerosis show increased expression of VCAM-1 on the choroid plexus vasculature and also harbor increased numbers of T cells and CD $138^{+}$plasma cells in their stroma [162]. Accumulation of innate and adaptive immune cells in the choroid plexus stroma in multiple sclerosis patients is associated with the appearance of increased numbers of memory/ effector T cells (Fig. 6) [51, 68], B cells, and antibodyproducing cells in the CSF of these patients [26], suggesting that immune cells that invade the ventricles have to eventually pass the choroid plexus epithelium. Indeed, mimicking the increase of CNS danger signals by intracerebroventricular injection of TNF- $\alpha$, besides eliciting an inflammatory response throughout the brain, leads to $\mathrm{T}$ cell accumulation in the choroid plexus stroma [169]. This further supports the important role of the choroid plexuses as key interphases for a bidirectional neuroimmune communication that may critically influence effector functions of those T cells locally activated within the choroid plexus stroma. The neuroimmune function of the choroid plexus is further underscored by the findings that in neuromyelitis optica, the BCSFB in the choroid plexus is significantly impaired [56].

Both ICAM-1 and VCAM-1 are constitutively expressed by choroid plexus epithelial cells and are significantly upregulated during EAE [144] and intriguingly also in CNS pathology remote to the choroid plexuses such as spinal cord injury [135]. In experimental spinal cord injury epithelial ICAM-1 and VCAM- 1 on choroid plexus epithelium have been proposed to mediate immune cell trafficking into the CNS in vivo [135]. ICAM-1 and VCAM-1 have previously been identified to mediate the multi-step $\mathrm{T}$ cell migration across the inflamed BBB endothelium during EAE [39]. In the choroid plexus, however, although both adhesion molecules are functionally expressed [144] they are exclusively localized to the apical surface of the choroid plexus epithelial cells and thus not readily accessible for immune cells within the choroid plexus stroma ([41], and Fig. 7). Apical ICAM-1 and VCAM-1 may thus mediate the egress of
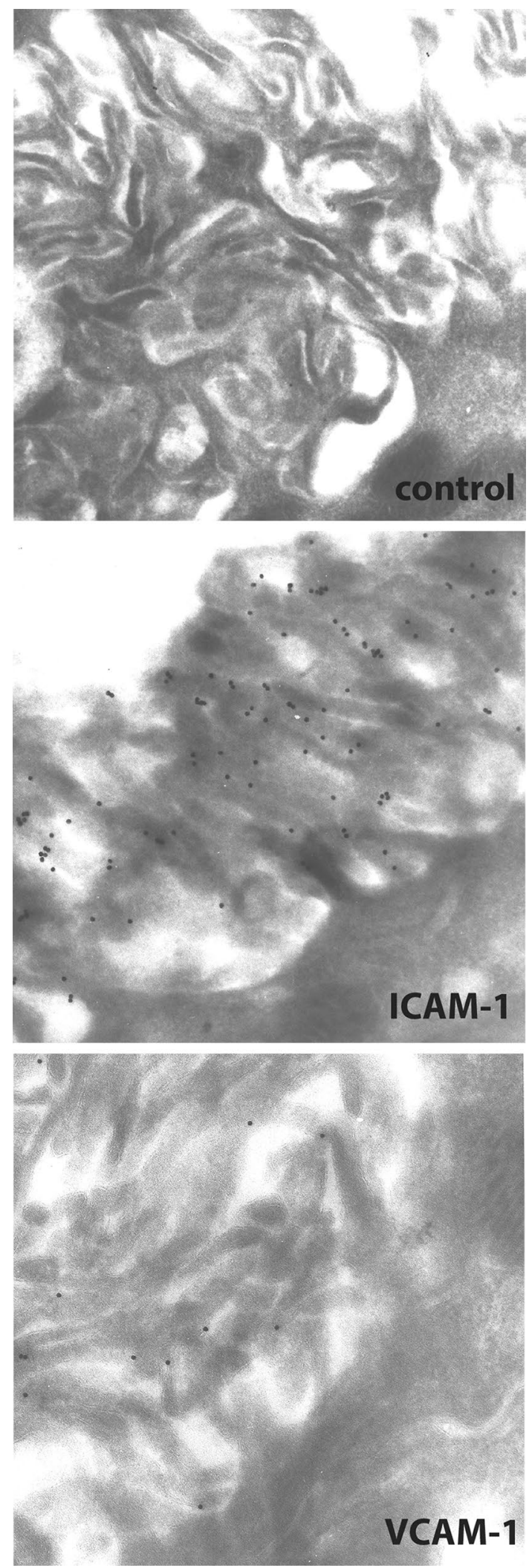

immune cells from the choroidal epithelial cells allowing them to be released into the CSF or alternatively serve as anchors for immune cells after having crossed the epithelium 
allowing them to resist the shear forces exerted by the CSF flow. In addition, apical ICAM-1 and VCAM-1 may be the source for soluble ICAM-1 and VCAM-1 found in increased concentrations in the CSF of patients with multiple sclerosis, viral encephalitis or bacterial meningitis [118, 125].

Additional observations in the context of EAE have supported a role for the BCSFB as CNS entry port for encephalitogenic CCR6 ${ }^{+}$Th17 cells during initiation of the disease [114]. The only known ligand for the chemokine receptor CCR6, the chemokine CCL20, is constitutively expressed at the BCSFB rather than the BBB implying that CCR6 ${ }^{+}$Th17 cells access the CNS via the choroid plexuses. In this context it is interesting to note that recognition of myelin oligodendrocyte glycoprotein (MOG) is limited to $\mathrm{CCR6}^{+}$circulating $\mathrm{T}$ cells in multiple sclerosis patients [122] and that $\mathrm{CCR}^{+}$ $\mathrm{T}$ cells are enriched in the CSF of multiple sclerosis patients [115]. On the other hand, CCR6 expression on CSF T cells does not strictly correlate with a Th17 phenotype [115]. Thus, the CCR6-CCL20 axis may be relevant for the CNS entry of additional CCR6 ${ }^{+} \mathrm{T}$ cell subsets, which is supported by the observation that $\mathrm{CNS}$ recruitment of $\mathrm{CCR} 6^{+} \mathrm{FoxP}^{+}$ regulatory $\mathrm{T}$ cells $\left(\mathrm{T}_{\text {regs }}\right)$ has also been shown to require CCR6 [163]. The observation that in EAE the CCR6-CCL20 axis plays a dual role mediating autoaggressive Th17 cell versus $\mathrm{T}$ reg cell entry into the CNS supports the notion of the BCSFB as a critical interphase integrating neuroimmune signals from the periphery and CNS, leading to immune cell activation or tolerance [25].

The choroid plexuses may play an additional role during neuroinflammation by specifically promoting the recruitment of regulatory or "healing" immune cells. Evidence for this concept has been provided by the observation that in spinal cord injury pro-inflammatory monocyte-derived $\left(\mathrm{Ly} 6 \mathrm{c}^{\mathrm{hi}} \mathrm{CX} 3 \mathrm{CR} 1^{\mathrm{lo}}\right.$ ) macrophages reached the injury site in a CCL2 dependent manner from the spinal cord leptomeninges, while the inflammatory-resolving (Ly6 $\mathrm{c}^{\mathrm{lo}} \mathrm{CX} 3 \mathrm{CR} 1^{\mathrm{hi}}$ ) monocyte-derived macrophages rather seemed to arrive to the injury site from the choroid plexuses in a $\alpha 4$-integrin/ VCAM-1 and CD73 dependent manner [135]. The site of injury may, however, be relevant for the function of the choroid plexuses in promoting anti-inflammatory or inflammatory cues. In traumatic brain injury a rapid increase in synthesis and release of diverse CXCL chemokines and CCL2 from the choroid plexus epithelium has been observed [154, $155]$ and was accompanied by the invasion of monocytes and neutrophils in between choroid plexus epithelial cells [154]. Pathogen-derived TLR ligands also induce an accumulation of innate immune cells in the CSF and choroid plexus in the developing brain [98]. Whether in the latter two situations, the recruitment of immune cells at the choroid plexuses is beneficial or deleterious to the brain remains to be established.
Accumulating evidence has supported the role of the choroid plexus as key invasion route for immune cells into the CNS. The mechanisms of endothelial and epithelial transmigration, however, are not fully elucidated. Few studies were able to provide direct evidence for the migration of immune cells from the choroid plexus stroma across the BCSFB into the ventricle in vivo $[154,155]$. Especially studies in EAE have failed to provide direct in vivo evidence for the localization of $\mathrm{T}$ cells between choroid plexus epithelial cells providing proof of their passage across the epithelium $[41,114]$. One EAE study even failed completely to detect any T cells in the choroid plexuses [128]. Another study found only a marginal increase in T cells in the stroma [129], that can be interpreted as the choroid plexuses being gateway to the CSF during EAE rather than sites of accumulation per se. On the other hand in vitro studies employing inverse configurations of the BCSFB have provided solid evidence for the migration of activated $\mathrm{T}$ cells from the basolateral to apical site of choroid plexus epithelial cells in response to CSF derived factors such as CXCL12 [77, 147]. These observations raise the question if there is an alternative route for T-cell entry into the CNS from the choroid plexus stroma.

Investigating T-cell invasion into the peri-infarct cortex after ischemic stroke by employing in vivo cell tracking of photactivated $\mathrm{T}$ cells has indeed provided evidence for a directed intracerebral migration of $\mathrm{T}$ cells from the ipsilateral choroid plexus stroma to the peri-infarct cortex [83]. A CCR2 ligand gradient between the choroid plexus stroma and the ischemic cortex was identified as the potential driving mechanism for $\mathrm{T}$ cell invasion. At the same time blocking CSF flow with matrigel failed to alter $\mathrm{T}$ cell invasion at the peri-ischemic site suggesting that $\mathrm{T}$ cell migration via ventricular CSF does not play a significant role in cerebral $\mathrm{T}$ cell invasion after stroke [83]. A route of immune cell entry from the choroid plexus stroma into the CNS other than passing through the epithelium, e.g. from the base of the choroid plexus thus should be investigated. It may, similarly to the postulated T-cell migration across the epithelium, contribute to the preferential localization of focal demyelinated plaques in periventricular areas in patients with multiple sclerosis [76].

Furthermore, there is emerging evidence that the choroid plexuses are relevant entry sites for pathogens, such as bacteria, viruses, fungi and parasites into the CNS [31]. A number of pathogens, including Streptococcus suis, Neisseria meningitidis, Haemophilus influenzae, Listeria monocytogenes, and Trypanosoma brucei, to just name a few, have been shown to use the choroidal epithelium as a CNS entry site (summarized in [131]). These pathogens may cross the epithelium directly via paracellular or transcellular routes or use Trojan horse approaches to breach the barrier [31]. The choroid plexus responds to these pathogens by eliciting a stereotype programmed innate inflammatory host 
response leading to an increased expression of cytokines and chemokines that trigger BCSFB breakdown and eventually to an increased CNS invasion of pathogenic inflammatory cells into the CNS. In this context, the direct response of the choroid plexuses to the infectious agents will in addition to CNS invasion of the pathogens contribute to the pathogenesis of these neuroinflammatory diseases [131].

Finally, in light of the significant contribution of the meninges in brain metastasis, a role of the choroid plexuses when considering the pathway of tumor cell invasion into the brain may be underestimated. Recent in vitro evidence supporting a role for the migration of neuroblastoma cells across the choroidal barrier [161] warrants further studies into the role of this barrier in tumor metastasis to the CNS.

\section{Conclusion}

The choroid plexuses have emerged as an underestimated interface fulfilling functions that are essential for CNS homeostasis both during development and in adulthood, and that extend far beyond those of a simple morphological barrier between the blood and the CSF. These functions include a protection of the brain from noxious compounds resulting from the capacity of the choroidal tissue to secrete CSF and from the coordinated action of tight junctions, efflux transporters, and detoxifying enzymes. The choroid plexuses are also providers of biologically active factors to both the developing and adult brain, and are capable of influencing stem cell proliferation and differentiation. Current findings support an important role for the choroid plexuses as sensors of homeostatic changes induced by different CNS insults. Finally, a growing body of evidence confers on the choroid plexuses a regulatory function in the balance of immune cell trafficking into the CNS during immune surveillance and in CNS pathology.

The efficacy of the epithelial tight junctions to form an efficient barrier between the blood and the CSF has been clearly established. Definite proofs of the in vivo relevance or efficacy of some of the other functions in both physiological and pathological contexts await the development of BCSFB-targeted animal models or tools. The studies realized in the last decade support the hypothesis that a functional dysregulation of the choroid plexuses may be a common mechanism involved in the pathophysiology of a large variety of neurological disorders. An in-depth understanding of choroid plexus functions should, therefore, be beneficial for unravelling the mechanisms associated with CNS diseases and related comorbidities.

Acknowledgements Light sheet fluorescence and Electron microscopy images have been generated at CIQLE facility, Lyon-1 University. We thank Sandrine Blondel for her excellent technical help in light sheet fluorescence microscopy.

Funding CESAME Grant (ANR-10-IBHU-0003) to JFGE. Swiss National Science Foundation (31003A_163088) and University of Basel to FD. Swiss National Science Foundation (PDFMP3_137127) and the Bangerter-Rhyner Foundation to BE.

\section{Compliance with ethical standards}

Conflict of interest The authors declare that they have no conflict of interest.

Open Access This article is distributed under the terms of the Creative Commons Attribution 4.0 International License (http://creativeco mmons.org/licenses/by/4.0/), which permits unrestricted use, distribution, and reproduction in any medium, provided you give appropriate credit to the original author(s) and the source, provide a link to the Creative Commons license, and indicate if changes were made.

\section{References}

1. Agrawal S, Anderson P, Durbeej M, van Rooijen N, Ivars F, Opdenakker G, Sorokin LM (2006) Dystroglycan is selectively cleaved at the parenchymal basement membrane at sites of leukocyte extravasation in experimental autoimmune encephalomyelitis. J Exp Med 203:1007-1019

2. Alix E, Schmitt C, Strazielle N, Ghersi-Egea JF (2008) Prostaglandin E2 metabolism in rat brain: role of the blood-brain interfaces. Cerebrospinal Fluid Res 5:5

3. Alvermann S, Hennig C, Stuve O, Wiendl H, Stangel M (2014) Immunophenotyping of cerebrospinal fluid cells in multiple sclerosis: in search of biomarkers. JAMA Neurol 71:905-912

4. Aoki I, Wu YJ, Silva AC, Lynch RM, Koretsky AP (2004) In vivo detection of neuroarchitecture in the rodent brain using manganese-enhanced MRI. Neuroimage 22:1046-1059

5. Balaban E, Teillet MA, Le Douarin N (1988) Application of the quail-chick chimera system to the study of brain development and behavior. Science 241:1339-1342

6. Balusu S, Van Wonterghem E, De Rycke R, Raemdonck K, Stremersch S, Gevaert K, Brkic M, Demeestere D, Vanhooren V, Hendrix A, Libert C, Vandenbroucke RE (2016) Identification of a novel mechanism of blood-brain communication during peripheral inflammation via choroid plexus-derived extracellular vesicles. EMBO Mol Med 8:1162-1183

7. Barkho BZ, Monuki ES (2015) Proliferation of cultured mouse choroid plexus epithelial cells. PLoS ONE 10:e0121738

8. Bartholomaus I, Kawakami N, Odoardi F, Schlager C, Miljkovic D, Ellwart JW, Klinkert WE, Flugel-Koch C, Issekutz TB, Wekerle H, Flugel A (2009) Effector T cell interactions with meningeal vascular structures in nascent autoimmune CNS lesions. Nature 462:94-98

9. Baruch K, Deczkowska A, David E, Castellano JM, Miller O, Kertser A, Berkutzki T, Barnett-Itzhaki Z, Bezalel D, WyssCoray T, Amit I, Schwartz M (2014) Aging. Aging-induced type I interferon response at the choroid plexus negatively affects brain function. Science 346:89-93

10. Baruch K, Ron-Harel N, Gal H, Deczkowska A, Shifrut E, Ndifon W, Mirlas-Neisberg N, Cardon M, Vaknin I, Cahalon L, Berkutzki T, Mattson MP, Gomez-Pinilla F, Friedman N, Schwartz M (2013) CNS-specific immunity at the choroid plexus shifts 
toward destructive Th2 inflammation in brain aging. Proc Natl Acad Sci USA 110:2264-2269

11. Batiz LF, Castro MA, Burgos PV, Velasquez ZD, Munoz RI, Lafourcade CA, Troncoso-Escudero P, Wyneken U (2015) Exosomes as novel regulators of adult neurogenic niches. Front Cell Neurosci 9:501

12. Bock NA, Paiva FF, Nascimento GC, Newman JD, Silva AC (2008) Cerebrospinal fluid to brain transport of manganese in a non-human primate revealed by MRI. Brain Res 1198:160-170 (Epub 2008 Jan 2004)

13. Braun JS, Kaissling B, Le Hir M, Zenker W (1993) Cellular components of the immune barrier in the spinal meninges and dorsal root ganglia of the normal rat: immunohistochemical (MHC class II) and electron-microscopic observations. Cell Tissue Res 273:209-217

14. Brown DA, Sawchenko PE (2007) Time course and distribution of inflammatory and neurodegenerative events suggest structural bases for the pathogenesis of experimental autoimmune encephalomyelitis. J Comp Neurol 502:236-260

15. Campos Y, Qiu X, Gomero E, Wakefield R, Horner L, Brutkowski W, Han YG, Solecki D, Frase S, Bongiovanni A, d'Azzo A (2016) Alix-mediated assembly of the actomyosin-tight junction polarity complex preserves epithelial polarity and epithelial barrier. Nat Commun 7:11876

16. Cepok S, Rosche B, Grummel V, Vogel F, Zhou D, Sayn J, Sommer N, Hartung HP, Hemmer B (2005) Short-lived plasma blasts are the main B cell effector subset during the course of multiple sclerosis. Brain 128:1667-1676

17. Chaker Z, Codega P, Doetsch F (2016) A mosaic world: puzzles revealed by adult neural stem cell heterogeneity. Wiley Interdiscip Rev Dev Biol 5:640-658

18. Chau KF, Springel MW, Broadbelt KG, Park HY, Topal S, Lun MP, Mullan H, Maynard T, Steen H, LaMantia AS, Lehtinen MK (2015) Progressive differentiation and instructive capacities of amniotic fluid and cerebrospinal fluid proteomes following neural tube closure. Dev Cell 35:789-802

19. Chaudhry A, Samstein RM, Treuting P, Liang Y, Pils MC, Heinrich JM, Jack RS, Wunderlich FT, Bruning JC, Muller W, Rudensky AY (2011) Interleukin-10 signaling in regulatory T cells is required for suppression of Th17 cell-mediated inflammation. Immunity 34:566-578

20. Chauhan AN, Lewis PD (1979) A quantitative study of cell proliferation in ependyma and choroid plexus in the postnatal rat brain. Neuropathol Appl Neurobiol 5:303-309

21. Chouaf-Lakhdar L, Fevre-Montange M, Brisson C, Strazielle N, Gamrani H, Didier-Bazes M (2003) Proliferative activity and nestin expression in periventricular cells of the adult rat brain. NeuroReport 14:633-636

22. Cobos I, Shimamura K, Rubenstein JL, Martinez S, Puelles L (2001) Fate map of the avian anterior forebrain at the four-somite stage, based on the analysis of quail-chick chimeras. Dev Biol 239:46-67

23. Codega P, Silva-Vargas V, Paul A, Maldonado-Soto AR, Deleo AM, Pastrana E, Doetsch F (2014) Prospective identification and purification of quiescent adult neural stem cells from their in vivo niche. Neuron 82:545-559

24. Coles JA, Myburgh E, Brewer JM, McMenamin PG (2017) Where are we? The anatomy of the murine cortical meninges revisited for intravital imaging, immunology, and clearance of waste from the brain. Prog Neurobiol 156:107-148

25. Comerford I, Bunting M, Fenix K, Haylock-Jacobs S, Litchfield W, Harata-Lee Y, Turvey M, Brazzatti J, Gregor C, Nguyen P, Kara E, McColl SR (2010) An immune paradox: how can the same chemokine axis regulate both immune tolerance and activation?: CCR6/CCL20: a chemokine axis balancing immunological tolerance and inflammation in autoimmune disease. BioEssays 32:1067-1076

26. Corcione A, Casazza S, Ferretti E, Giunti D, Zappia E, Pistorio A, Gambini C, Mancardi GL, Uccelli A, Pistoia V (2004) Recapitulation of B cell differentiation in the central nervous system of patients with multiple sclerosis. Proc Natl Acad Sci USA 101:11064-11069

27. Couly G, Coltey P, Eichmann A, Le Douarin NM (1995) The angiogenic potentials of the cephalic mesoderm and the origin of brain and head blood vessels. Mech Dev 53:97-112

28. Couly GF, Coltey PM, Le Douarin NM (1992) The developmental fate of the cephalic mesoderm in quail-chick chimeras. Development 114:1-15

29. Couly GF, Le Douarin NM (1987) Mapping of the early neural primordium in quail-chick chimeras. II. The prosencephalic neural plate and neural folds: implications for the genesis of cephalic human congenital abnormalities. Dev Biol 120:198-214

30. Currle DS, Cheng X, Hsu CM, Monuki ES (2005) Direct and indirect roles of CNS dorsal midline cells in choroid plexus epithelia formation. Development 132:3549-3559

31. Dahm T, Rudolph H, Schwerk C, Schroten H, Tenenbaum T (2016) Neuroinvasion and inflammation in viral central nervous system infections. Med Inflamm 2016:8562805

32. Davson H, Segal MB (1996) Physiology of the CSF and the blood-brain barriers. CRC Press, Boca Raton

33. de Graaf MT, Smitt PA, Luitwieler RL, van Velzen C, van den Broek PD, Kraan J, Gratama JW (2011) Central memory $\mathrm{CD} 4+\mathrm{T}$ cells dominate the normal cerebrospinal fluid. Cytometry B Clin Cytom 80:43-50

34. Deczkowska A, Baruch K, Schwartz M (2016) Type I/II interferon balance in the regulation of brain physiology and pathology. Trends Immunol 37:181-192

35. Delgado AC, Ferron SR, Vicente D, Porlan E, Perez-Villalba A, Trujillo CM, D'Ocon P, Farinas I (2014) Endothelial NT-3 delivered by vasculature and CSF promotes quiescence of subependymal neural stem cells through nitric oxide induction. Neuron 83:572-585

36. Engelhardt B (2001) The choroid plexus in health and disease. Microcopy research and technique, vol 52. Wiley-Liss, New York

37. Engelhardt B, Carare RO, Bechmann I, Flugel A, Laman JD, Weller RO (2016) Vascular, glial, and lymphatic immune gateways of the central nervous system. Acta Neuropathol 132:317-338

38. Engelhardt B, Coisne C (2011) Fluids and barriers of the CNS establish immune privilege by confining immune surveillance to a two-walled castle moat surrounding the CNS castle. Fluids and Barriers of the CNS 8

39. Engelhardt B, Ransohoff RM (2012) Capture, crawl, cross: the $\mathrm{T}$ cell code to breach the blood-brain barriers. Trends Immunol 33:579-589

40. Engelhardt B, Vajkoczy P, Weller RO (2017) The movers and shapers in immune privilege of the CNS. Nat Immunol 18:123-131

41. Engelhardt B, Wolburg-Buchholz K, Wolburg H (2001) Involvement of the choroid plexus in central nervous system inflammation. Microsc Res Tech 52:112-129

42. Ennis SR, Keep RF (2006) The effects of cerebral ischemia on the rat choroid plexus. J Cereb Blood Flow Metab 26:675-683

43. Faubel R, Westendorf C, Bodenschatz E, Eichele G (2016) Ciliabased flow network in the brain ventricles. Science 353:176-178

44. Gazzin S, Strazielle N, Schmitt C, Fevre-Montange M, Ostrow JD, Tiribelli C, Ghersi-Egea JF (2008) Differential expression of the multidrug resistance-related proteins $\mathrm{ABCb} 1$ and $\mathrm{ABCc} 1$ between blood-brain interfaces. J Comp Neurol 510:497-507 
45. Gazzin S, Strazielle N, Tiribelli C, Ghersi-Egea JF (2012) Transport and metabolism at blood-brain interfaces and in neural cells: relevance to bilirubin-induced encephalopathy. Front Pharmacol 3:89

46. Ghersi-Egea JF, Babikian A, Blondel S, Strazielle N (2015) Changes in the cerebrospinal fluid circulatory system of the developing rat: quantitative volumetric analysis and effect on blood-CSF permeability interpretation. Fluids Barriers CNS 12:8

47. Ghersi-Egea JF, Damkier HH (2017) Blood-brain interfaces organization in relation to inorganic ion transport, CSF secretion, and circulation. Brain edema. From molecular mechanisms to clinical practice. Academic Press, Oxford

48. Ghersi-Egea JF, Finnegan W, Chen JL, Fenstermacher JD (1996) Rapid distribution of intraventricularly administered sucrose into cerebrospinal fluid cisterns via subarachnoid velae in rat. Neuroscience 75:1271-1288

49. Ghersi-Egea JF, Gorevic PD, Ghiso J, Frangione B, Patlak CS, Fenstermacher JD (1996) Fate of cerebrospinal fluidborne amyloid beta-peptide: rapid clearance into blood and appreciable accumulation by cerebral arteries. J Neurochem 67:880-883

50. Ghersi-Egea JF, Strazielle N, Murat A, Jouvet A, Buenerd A, Belin MF (2006) Brain protection at the blood-cerebrospinal fluid interface involves a glutathione-dependent metabolic barrier mechanism. J Cereb Blood Flow Metab 26:1165-1175

51. Giunti D, Borsellino G, Benelli R, Marchese M, Capello E, Valle MT, Pedemonte E, Noonan D, Albini A, Bernardi G, Mancardi GL, Battistini L, Uccelli A (2003) Phenotypic and functional analysis of T cells homing into the CSF of subjects with inflammatory diseases of the CNS. J Leukoc Biol 73:584-590

52. Goldmann T, Wieghofer P, Jordao MJ, Prutek F, Hagemeyer N, Frenzel K, Amann L, Staszewski O, Kierdorf K, Krueger M, Locatelli G, Hochgerner H, Zeiser R, Epelman S, Geissmann F, Priller J, Rossi FM, Bechmann I, Kerschensteiner M, Linnarsson S, Jung S, Prinz M (2016) Origin, fate and dynamics of macrophages at central nervous system interfaces. Nat Immunol 17:797-805

53. Gonzalez-Marrero I, Gimenez-Llort L, Johanson CE, CarmonaCalero EM, Castaneyra-Ruiz L, Brito-Armas JM, CastaneyraPerdomo A, Castro-Fuentes R (2015) Choroid plexus dysfunction impairs beta-amyloid clearance in a triple transgenic mouse model of Alzheimer's disease. Front Cell Neurosci 9:17

54. Grapp M, Just IA, Linnankivi T, Wolf P, Lucke T, Hausler M, Gartner J, Steinfeld R (2012) Molecular characterization of folate receptor 1 mutations delineates cerebral folate transport deficiency. Brain 135:2022-2031

55. Grapp M, Wrede A, Schweizer M, Huwel S, Galla HJ, Snaidero N, Simons M, Buckers J, Low PS, Urlaub H, Gartner J, Steinfeld R (2013) Choroid plexus transcytosis and exosome shuttling deliver folate into brain parenchyma. Nat Commun 4:2123

56. Guo Y, Weigand SD, Popescu BF, Lennon VA, Parisi JE, Pittock SJ, Parks NE, Clardy SL, Howe CL, Lucchinetti CF (2017) Pathogenic implications of cerebrospinal fluid barrier pathology in neuromyelitis optica. Acta Neuropathol 133:597-612

57. Han H, Kim SG, Lee MG, Shim CK, Chung SJ (2002) Mechanism of the reduced elimination clearance of benzylpenicillin from cerebrospinal fluid in rats with intracisternal administration of lipopolysaccharide. Drug Metab Dispos 30:1214-1220

58. Hasselblatt M, Mertsch S, Koos B, Riesmeier B, Stegemann H, Jeibmann A, Tomm M, Schmitz N, Wrede B, Wolff JE, Zheng W, Paulus W (2009) TWIST-1 is overexpressed in neoplastic choroid plexus epithelial cells and promotes proliferation and invasion. Cancer Res 69:2219-2223

59. Huang X, Liu J, Ketova T, Fleming JT, Grover VK, Cooper MK, Litingtung Y, Chiang C (2010) Transventricular delivery of Sonic hedgehog is essential to cerebellar ventricular zone development. Proc Natl Acad Sci USA 107:8422-8427

60. Imayoshi I, Shimogori T, Ohtsuka T, Kageyama R (2008) Hes genes and neurogenin regulate non-neural versus neural fate specification in the dorsal telencephalic midline. Development $135: 2531-2541$

61. Iwamoto N, Higashi T, Furuse M (2014) Localization of angulin-1/LSR and tricellulin at tricellular contacts of brain and retinal endothelial cells in vivo. Cell Struct Funct 39:1-8

62. Japp AS, Klein-Hitpass L, Denkhaus D, Pietsch T (2017) OTX2 defines a subgroup of atypical teratoid rhabdoid tumors with close relationship to choroid plexus tumors. J Neuropathol Exp Neurol 76:32-38

63. Johansson PA (2014) The choroid plexuses and their impact on developmental neurogenesis. Front Neurosci 8:340

64. Johansson PA, Irmler M, Acampora D, Beckers J, Simeone A, Gotz M (2013) The transcription factor Otx2 regulates choroid plexus development and function. Development 140:1055-1066

65. Kaur C, Ling EA (2017) The circumventricular organs. Histol Histopathol 32:879-892

66. Keep RF, Jones HC (1990) A morphometric study on the development of the lateral ventricle choroid plexus, choroid plexus capillaries and ventricular ependyma in the rat. Brain Res Dev Brain Res 56:47-53

67. Khuth ST, Strazielle N, Giraudon P, Belin MF, Ghersi-Egea JF (2005) Impairment of blood-cerebrospinal fluid barrier properties by retrovirus-activated $\mathrm{T}$ lymphocytes: reduction in cerebrospinal fluid-to-blood efflux of prostaglandin E2. J Neurochem 94:1580-1593

68. Kivisakk P, Mahad DJ, Callahan MK, Trebst C, Tucky B, Wei T, Wu L, Baekkevold ES, Lassmann H, Staugaitis SM, Campbell JJ, Ransohoff RM (2003) Human cerebrospinal fluid central memory CD4 + T cells: evidence for trafficking through choroid plexus and meninges via P-selectin. Proc Natl Acad Sci USA 100:8389-8394

69. Kokovay E, Wang Y, Kusek G, Wurster R, Lederman P, Lowry $\mathrm{N}$, Shen Q, Temple S (2012) VCAM1 is essential to maintain the structure of the SVZ niche and acts as an environmental sensor to regulate SVZ lineage progression. Cell Stem Cell 11:220-230

70. Kolmer W (1921) Über eine eigenartige Beziehung von Wanderzellen zu den Choroidealplexus des Gehirns der Wirbeltiere. Anat Anz 54:15-19

71. Kooij G, Kopplin K, Blasig R, Stuiver M, Koning N, Goverse G, van der Pol SM, van Het Hof B, Gollasch M, Drexhage JA, Reijerkerk A, Meij IC, Mebius R, Willnow TE, Muller D, Blasig IE, de Vries HE (2014) Disturbed function of the blood-cerebrospinal fluid barrier aggravates neuro-inflammation. Acta Neuropathol 128:267-277

72. Korzhevskii DE (2000) Proliferative zones in the epithelium of the choroid plexuses of the human embryo brain. Neurosci Behav Physiol 30:509-512

73. Kratzer I, Liddelow SA, Saunders NR, Dziegielewska KM, Strazielle N, Ghersi-Egea JF (2013) Developmental changes in the transcriptome of the rat choroid plexus in relation to neuroprotection. Fluids Barriers CNS 10:25

74. Kratzer I, Vasiljevic A, Rey C, Fevre-Montange M, Saunders N, Strazielle N, Ghersi-Egea JF (2012) Complexity and developmental changes in the expression pattern of claudins at the blood-CSF barrier. Histochem Cell Biol 138:861-879

75. Kunis G, Baruch K, Rosenzweig N, Kertser A, Miller O, Berkutzki T, Schwartz M (2013) IFN-gamma-dependent activation of the brain's choroid plexus for CNS immune surveillance and repair. Brain 136:3427-3440

76. Kutzelnigg A, Lassmann H (2005) Cortical lesions and brain atrophy in MS. J Neurol Sci 233:55-59 
77. Lazarevic I, Engelhardt B (2016) Modeling immune functions of the mouse blood-cerebrospinal fluid barrier in vitro: primary rather than immortalized mouse choroid plexus epithelial cells are suited to study immune cell migration across this brain barrier. Fluids Barriers CNS 13:2

78. Lehtinen MK, Zappaterra MW, Chen X, Yang YJ, Hill AD, Lun M, Maynard T, Gonzalez D, Kim S, Ye P, D'Ercole AJ, Wong ET, LaMantia AS, Walsh CA (2011) The cerebrospinal fluid provides a proliferative niche for neural progenitor cells. Neuron 69:893-905

79. Li Y, Chen J, Chopp M (2002) Cell proliferation and differentiation from ependymal, subependymal and choroid plexus cells in response to stroke in rats. J Neurol Sci 193:137-146

80. Liddelow SA, Dziegielewska KM, Ek CJ, Habgood MD, Bauer H, Bauer HC, Lindsay H, Wakefield MJ, Strazielle N, Kratzer I, Mollgard K, Ghersi-Egea JF, Saunders NR (2013) Mechanisms that determine the internal environment of the developing brain: a transcriptomic, functional and ultrastructural approach. PLoS ONE 8:e65629

81. Lindvall M, Hardebo JE, Owman C (1980) Barrier mechanisms for neutrotransmitter monoamines in the choroid plexus. Acta Physiol Scand 108:215-221

82. Lippoldt A, Liebner S, Andbjer B, Kalbacher H, Wolburg H, Haller H, Fuxe K (2000) Organization of choroid plexus epithelial and endothelial cell tight junctions and regulation of claudin-1, -2 and -5 expression by protein kinase C. NeuroReport 11:1427-1431

83. Llovera G, Benakis C, Enzmann G, Cai R, Arzberger T, Ghasemigharagoz A, Mao X, Malik R, Lazarevic I, Liebscher S, Erturk A, Meissner L, Vivien D, Haffner C, Plesnila N, Montaner J, Engelhardt B, Liesz A (2017) The choroid plexus is a key cerebral invasion route for $\mathrm{T}$ cells after stroke. Acta Neuropathol 134:851-868

84. Lodygin D, Odoardi F, Schlager C, Korner H, Kitz A, Nosov M, van den Brandt J, Reichardt HM, Haberl M, Flugel A (2013) A combination of fluorescent NFAT and H2B sensors uncovers dynamics of $\mathrm{T}$ cell activation in real time during CNS autoimmunity. Nat Med 19:784-790

85. Lun MP, Johnson MB, Broadbelt KG, Watanabe M, Kang YJ, Chau KF, Springel MW, Malesz A, Sousa AM, Pletikos M, Adelita T, Calicchio ML, Zhang Y, Holtzman MJ, Lidov HG, Sestan N, Steen H, Monuki ES, Lehtinen MK (2015) Spatially heterogeneous choroid plexus transcriptomes encode positional identity and contribute to regional CSF production. J Neurosci 35:4903-4916

86. Maharaj AS, Walshe TE, Saint-Geniez M, Venkatesha S, Maldonado AE, Himes NC, Matharu KS, Karumanchi SA, D'Amore PA (2008) VEGF and TGF-beta are required for the maintenance of the choroid plexus and ependyma. J Exp Med 205:491-501

87. Marin F, Puelles L (1995) Morphological fate of rhombomeres in quail/chick chimeras: a segmental analysis of hindbrain nuclei. Eur J Neurosci 7:1714-1738

88. Marques F, Sousa JC (2015) The choroid plexus is modulated by various peripheral stimuli: implications to diseases of the central nervous system. Front Cell Neurosci 9:136

89. Marques F, Sousa JC, Coppola G, Falcao AM, Rodrigues AJ, Geschwind DH, Sousa N, Correia-Neves M, Palha JA (2009) Kinetic profile of the transcriptome changes induced in the choroid plexus by peripheral inflammation. J Cereb Blood Flow Metab 29:921-932

90. Martin C, Bueno D, Alonso MI, Moro JA, Callejo S, Parada C, Martin P, Carnicero E, Gato A (2006) FGF2 plays a key role in embryonic cerebrospinal fluid trophic properties over chick embryo neuroepithelial stem cells. Dev Biol 297:402-416
91. Matsumoto K, Chiba Y, Fujihara R, Kubo H, Sakamoto H, Ueno M (2015) Immunohistochemical analysis of transporters related to clearance of amyloid-beta peptides through bloodcerebrospinal fluid barrier in human brain. Histochem Cell Biol 144:597-611

92. McBratney-Owen B, Iseki S, Bamforth SD, Olsen BR, MorrissKay GM (2008) Development and tissue origins of the mammalian cranial base. Dev Biol 322:121-132

93. Millward JM, Schnorr J, Taupitz M, Wagner S, Wuerfel JT, Infante-Duarte $C$ (2013) Iron oxide magnetic nanoparticles highlight early involvement of the choroid plexus in central nervous system inflammation. ASN Neuro 5:e0110

94. Miyamoto T, Morita K, Takemoto D, Takeuchi K, Kitano Y, Miyakawa T, Nakayama K, Okamura Y, Sasaki H, Miyachi Y, Furuse M, Tsukita S (2005) Tight junctions in Schwann cells of peripheral myelinated axons: a lesson from claudin-19-deficient mice. J Cell Biol 169:527-538

95. Miyata S (2015) New aspects in fenestrated capillary and tissue dynamics in the sensory circumventricular organs of adult brains. Front Neurosci 9:390

96. Moalem G, Leibowitz-Amit R, Yoles E, Mor F, Cohen IR, Schwartz M (1999) Autoimmune T cells protect neurons from secondary degeneration after central nervous system axotomy. Nat Med 5:49-55

97. Mollgard K, Saunders NR (1986) The development of the human blood-brain and blood-CSF barriers. Neuropathol Appl Neurobiol 12:337-358

98. Mottahedin A, Smith PL, Hagberg H, Ek CJ, Mallard C (2017) TLR2-mediated leukocyte trafficking to the developing brain. J Leukoc Biol 101:297-305

99. Muto S, Hata M, Taniguchi J, Tsuruoka S, Moriwaki K, Saitou M, Furuse K, Sasaki H, Fujimura A, Imai M, Kusano E, Tsukita S, Furuse M (2010) Claudin-2-deficient mice are defective in the leaky and cation-selective paracellular permeability properties of renal proximal tubules. Proc Natl Acad Sci USA 107:8011-8016

100. Nataf S, Strazielle N, Hatterer E, Mouchiroud G, Belin MF, Ghersi-Egea JF (2006) Rat choroid plexuses contain myeloid progenitors capable of differentiation toward macrophage or dendritic cell phenotypes. Glia 54:160-171

101. Nathanson JA, Chun LL (1989) Immunological function of the blood-cerebrospinal fluid barrier. Proc Natl Acad Sci USA 86:1684-1688

102. Nonami Y, Narita K, Nakamura H, Inoue T, Takeda S (2013) Developmental changes in ciliary motility on choroid plexus epithelial cells during the perinatal period. Cytoskeleton 70:797-803

103. Oshio K, Watanabe H, Song Y, Verkman AS, Manley GT (2005) Reduced cerebrospinal fluid production and intracranial pressure in mice lacking choroid plexus water channel Aquaporin-1. FASEB J 19:76-78

104. Paredes MF, Sorrells SF, Garcia-Verdugo JM, Alvarez-Buylla A (2016) Brain size and limits to adult neurogenesis. J Comp Neurol 524:646-664

105. Paul A, Chaker Z, Doetsch F (2017) Hypothalamic regulation of regionally distinct adult neural stem cells and neurogenesis. Science 356:1383-1386

106. Pei L, Solis G, Nguyen MT, Kamat N, Magenheimer L, Zhuo M, Li J, Curry J, McDonough AA, Fields TA, Welch WJ, Yu AS (2016) Paracellular epithelial sodium transport maximizes energy efficiency in the kidney. J Clin Investig 126:2509-2518

107. Pesic M, Bartholomaus I, Kyratsous NI, Heissmeyer V, Wekerle H, Kawakami N (2013) 2-photon imaging of phagocyte-mediated $\mathrm{T}$ cell activation in the CNS. J Clin Investig 123:1192-1201

108. Praetorius J, Damkier HH (2017) Transport across the choroid plexus epithelium. Am J Physiol Cell Physiol 312:C673-C686 
109. Prinz M, Priller J, Sisodia SS, Ransohoff RM (2011) Heterogeneity of CNS myeloid cells and their roles in neurodegeneration. Nat Neurosci 14:1227-1235

110. Provencio JJ, Kivisakk P, Tucky BH, Luciano MG, Ransohoff RM (2005) Comparison of ventricular and lumbar cerebrospinal fluid $\mathrm{T}$ cells in non-inflammatory neurological disorder (NIND) patients. J Neuroimmunol 163:179-184

111. Quintela T, Marcelino H, Deery MJ, Feret R, Howard J, Lilley KS, Albuquerque T, Goncalves I, Duarte AC, Santos CR (2016) Sex-related differences in rat choroid plexus and cerebrospinal fluid: a cDNA microarray and proteomic analysis. J Neuroendocrinol. https://doi.org/10.1111/jne.1234

112. Quintela T, Sousa C, Patriarca FM, Goncalves I, Santos CR (2015) Gender associated circadian oscillations of the clock genes in rat choroid plexus. Brain Struct Funct 220:1251-1262

113. Ransohoff RM, Engelhardt B (2012) The anatomical and cellular basis of immune surveillance in the central nervous system. Nat Rev Immunol 12:623-635

114. Reboldi A, Coisne C, Baumjohann D, Benvenuto F, Bottinelli D, Lira S, Uccelli A, Lanzavecchia A, Engelhardt B, Sallusto F (2009) C-C chemokine receptor 6-regulated entry of TH-17 cells into the CNS through the choroid plexus is required for the initiation of EAE. Nat Immunol 10:514-523

115. Restorick SM, Durant L, Kalra S, Hassan-Smith G, Rathbone E, Douglas MR, Curnow SJ (2017) CCR6 + Th cells in the cerebrospinal fluid of persons with multiple sclerosis are dominated by pathogenic non-classic Th1 cells and GM-CSF-only-secreting Th cells. Brain Behav Immun 64:71-79

116. Richard K, Hume R, Kaptein E, Stanley EL, Visser TJ, Coughtrie MW (2001) Sulfation of thyroid hormone and dopamine during human development: ontogeny of phenol sulfotransferases and arylsulfatase in liver, lung, and brain. J Clin Endocrinol Metab 86:2734-2742

117. Richardson SJ, Wijayagunaratne RC, D'Souza DG, Darras VM, Van Herck SL (2015) Transport of thyroid hormones via the choroid plexus into the brain: the roles of transthyretin and thyroid hormone transmembrane transporters. Front Neurosci 9:66

118. Rieckmann P, Nunke K, Burchhardt M, Albrecht M, Wiltfang J, Ulrich M, Felgenhauer K (1993) Soluble intercellular adhesion molecule-1 in cerebrospinal fluid: an indicator for the inflammatory impairment of the blood-cerebrospinal fluid barrier. $\mathbf{J}$ Neuroimmunol 47:133-140

119. Roberts LM, Black DS, Raman C, Woodford K, Zhou M, Haggerty JE, Yan AT, Cwirla SE, Grindstaff KK (2008) Subcellular localization of transporters along the rat blood-brain barrier and blood-cerebral-spinal fluid barrier by in vivo biotinylation. Neuroscience 155:423-438

120. Rosenthal R, Gunzel D, Krug SM, Schulzke JD, Fromm M, Yu AS (2017) Claudin-2-mediated cation and water transport share a common pore. Acta Physiol 219:521-536

121. Rosenthal R, Gunzel D, Theune D, Czichos C, Schulzke JD, Fromm M (2017) Water channels and barriers formed by claudins. Ann N Y Acad Sci 1397:100-109

122. Sallusto F, Impellizzieri D, Basso C, Laroni A, Uccelli A, Lanzavecchia A, Engelhardt B (2012) T-cell trafficking in the central nervous system. Immunol Rev 248:216-227

123. Sallusto F, Lenig D, Forster R, Lipp M, Lanzavecchia A (1999) Two subsets of memory $\mathrm{T}$ lymphocytes with distinct homing potentials and effector functions. Nature 401:708-712

124. Santos CR, Duarte AC, Quintela T, Tomas J, Albuquerque T, Marques F, Palha JA, Goncalves I (2017) The choroid plexus as a sex hormone target: functional implications. Front Neuroendocrinol 44:103-121

125. Sasseville VG, Newman WA, Lackner AA, Smith MO, Lausen NC, Beall D, Ringler DJ (1992) Elevated vascular cell adhesion molecule-1 in AIDS encephalitis induced by simian immunodeficiency virus. Am J Pathol 141:1021-1030

126. Saunders NR, Habgood MD, Dziegielewska KM (1999) Barrier mechanisms in the brain, II. Immature brain. Clin Exp Pharmacol Physiol 26:85-91

127. Sawamoto K, Wichterle H, Gonzalez-Perez O, Cholfin JA, Yamada M, Spassky N, Murcia NS, Garcia-Verdugo JM, Marin O, Rubenstein JL, Tessier-Lavigne M, Okano H, Alvarez-Buylla A (2006) New neurons follow the flow of cerebrospinal fluid in the adult brain. Science 311:629-632

128. Schlager C, Korner H, Krueger M, Vidoli S, Haberl M, Mielke D, Brylla E, Issekutz T, Cabanas C, Nelson PJ, Ziemssen T, Rohde V, Bechmann I, Lodygin D, Odoardi F, Flugel A (2016) Effector T-cell trafficking between the leptomeninges and the cerebrospinal fluid. Nature 530:349-353

129. Schmitt C, Strazielle N, Ghersi-Egea JF (2012) Brain leukocyte infiltration initiated by peripheral inflammation or experimental autoimmune encephalomyelitis occurs through pathways connected to the CSF-filled compartments of the forebrain and midbrain. J Neuroinflammation 9:187

130. Schwartz M, Baruch K (2014) The resolution of neuroinflammation in neurodegeneration: leukocyte recruitment via the choroid plexus. EMBO J 33:7-22

131. Schwerk C, Tenenbaum T, Kim KS, Schroten H (2015) The choroid plexus-a multi-role player during infectious diseases of the CNS. Front Cell Neurosci 9:80

132. Serot JM, Bene MC, Foliguet B, Faure GC (2000) Morphological alterations of the choroid plexus in late-onset Alzheimer's disease. Acta Neuropathol 99:105-108

133. Serot JM, Foliguet B, Bene MC, Faure GC (1997) Ultrastructural and immunohistological evidence for dendritic-like cells within human choroid plexus epithelium. NeuroReport 8:1995-1998

134. Serot JM, Zmudka J, Jouanny P (2012) A possible role for CSF turnover and choroid plexus in the pathogenesis of late onset Alzheimer's disease. J Alzheimers Dis 30:17-26

135. Shechter R, Miller O, Yovel G, Rosenzweig N, London A, Ruckh J, Kim KW, Klein E, Kalchenko V, Bendel P, Lira SA, Jung S, Schwartz M (2013) Recruitment of beneficial M2 macrophages to injured spinal cord is orchestrated by remote brain choroid plexus. Immunity 38:555-569

136. Shuangshoti S, Netsky MG (1966) Histogenesis of choroid plexus in man. Am J Anat 118:283-316

137. Silva-Vargas V, Maldonado-Soto AR, Mizrak D, Codega P, Doetsch F (2016) Age-dependent niche signals from the choroid plexus regulate adult neural stem cells. Cell Stem Cell 19:643-652

138. Skipor J, Thiery JC (2008) The choroid plexus-cerebrospinal fluid system: undervaluated pathway of neuroendocrine signaling into the brain. Acta Neurobiol Exp 68:414-428

139. Smith DE, Hu Y, Shen H, Nagaraja TN, Fenstermacher JD, Keep RF (2011) Distribution of glycylsarcosine and cefadroxil among cerebrospinal fluid, choroid plexus, and brain parenchyma after intracerebroventricular injection is markedly different between wild-type and Pept2 null mice. J Cereb Blood Flow Metab $31: 250-261$

140. Spatazza J, Lee HH, Di Nardo AA, Tibaldi L, Joliot A, Hensch TK, Prochiantz A (2013) Choroid-plexus-derived Otx2 homeoprotein constrains adult cortical plasticity. Cell Rep 3:1815-1823

141. Spector R, Johanson CE (2010) Choroid plexus failure in the Kearns-Sayre syndrome. Cerebrospinal Fluid Res 7:14

142. Spector R, Johanson CE (2014) The nexus of vitamin homeostasis and DNA synthesis and modification in mammalian brain. Mol Brain 7:3

143. Stan RV, Tse D, Deharvengt SJ, Smits NC, Xu Y, Luciano MR, McGarry CL, Buitendijk M, Nemani KV, Elgueta R, Kobayashi 
T, Shipman SL, Moodie KL, Daghlian CP, Ernst PA, Lee HK, Suriawinata AA, Schned AR, Longnecker DS, Fiering SN, Noelle RJ, Gimi B, Shworak NW, Carriere C (2012) The diaphragms of fenestrated endothelia: gatekeepers of vascular permeability and blood composition. Dev Cell 23:1203-1218

144. Steffen BJ, Breier G, Butcher EC, Schulz M, Engelhardt B (1996) ICAM-1, VCAM-1, and MAdCAM-1 are expressed on choroid plexus epithelium but not endothelium and mediate binding of lymphocytes in vitro. Am J Pathol 148:1819-1838

145. Steinbach K, Vincenti I, Kreutzfeldt M, Page N, Muschaweckh A, Wagner I, Drexler I, Pinschewer D, Korn T, Merkler D (2016) Brain-resident memory $\mathrm{T}$ cells represent an autonomous cytotoxic barrier to viral infection. J Exp Med 213:1571-1587

146. Steinemann A, Galm I, Chip S, Nitsch C, Maly IP (2016) Claudin-1, -2 and -3 are selectively expressed in the epithelia of the choroid plexus of the mouse from early development and into adulthood while claudin-5 is restricted to endothelial cells. Front Neuroanat 10:16

147. Strazielle N, Creidy R, Malcus C, Boucraut J, Ghersi-Egea JF (2016) T-Lymphocytes traffic into the brain across the blood-CSF barrier: evidence using a reconstituted choroid plexus epithelium. PLoS ONE 11:e0150945

148. Strazielle N, Ghersi-Egea JF (1999) Demonstration of a coupled metabolism-efflux process at the choroid plexus as a mechanism of brain protection toward xenobiotics. J Neurosci 19:6275-6289

149. Strazielle N, Ghersi-Egea JF (2013) Physiology of blood-brain interfaces in relation to brain disposition of small compounds and macromolecules. Mol Pharm 10:1473-1491

150. Strazielle N, Ghersi-Egea JF (2015) Efflux transporters in bloodbrain interfaces of the developing brain. Front Neurosci 9:21

151. Stridh L, Ek CJ, Wang X, Nilsson H, Mallard C (2013) Regulation of Toll-like receptors in the choroid plexus in the immature brain after systemic inflammatory stimuli. Transl Stroke Res 4:220-227

152. Su P, Zhao F, Cao Z, Zhang J, Aschner M, Luo W (2015) Mir203-mediated tricellulin mediates lead-induced in vitro loss of blood-cerebrospinal fluid barrier (BCB) function. Toxicol In Vitro 29:1185-1194

153. Szmydynger-Chodobska J, Chodobski A, Johanson CE (1994) Postnatal developmental changes in blood flow to choroid plexuses and cerebral cortex of the rat. Am J Physiol 266:R1488-R1492

154. Szmydynger-Chodobska J, Strazielle N, Gandy JR, Keefe TH, Zink BJ, Ghersi-Egea JF, Chodobski A (2012) Posttraumatic invasion of monocytes across the blood-cerebrospinal fluid barrier. J Cereb Blood Flow Metab 32:93-104

155. Szmydynger-Chodobska J, Strazielle N, Zink BJ, Ghersi-Egea JF, Chodobski A (2009) The role of the choroid plexus in neutrophil invasion after traumatic brain injury. J Cereb Blood Flow Metab 29:1503-1516

156. Tachikawa M, Ozeki G, Higuchi T, Akanuma S, Tsuji K, Hosoya K (2012) Role of the blood-cerebrospinal fluid barrier transporter as a cerebral clearance system for prostaglandin $\mathrm{E}(2)$ produced in the brain. J Neurochem 123:750-760

157. Tang YP, Haslam SZ, Conrad SE, Sisk CL (2004) Estrogen increases brain expression of the mRNA encoding transthyretin, an amyloid beta scavenger protein. J Alzheimers Dis 6:413-420 (discussion 443-419)

158. Tayarani I, Cloez I, Clement M, Bourre JM (1989) Antioxidant enzymes and related trace elements in aging brain capillaries and choroid plexus. J Neurochem 53:817-824
159. Uchida Y, Zhang Z, Tachikawa M, Terasaki T (2015) Quantitative targeted absolute proteomics of rat blood-cerebrospinal fluid barrier transporters: comparison with a human specimen. J Neurochem 134:1104-1115

160. Usui T, Nakazawa A, Okura T, Deguchi Y, Akanuma SI, Kubo Y, Hosoya KI (2016) Histamine elimination from the cerebrospinal fluid across the blood-cerebrospinal fluid barrier: involvement of plasma membrane monoamine transporter (PMAT/SLC29A4). J Neurochem 139:408-418

161. Vandenhaute E, Stump-Guthier C, Losada ML, Tenenbaum T, Rudolph H, Ishikawa H, Schwerk C, Schroten H, Durken M, Marz M, Karremann M (2015) The choroid plexus may be an underestimated site of tumor invasion to the brain: an in vitro study using neuroblastoma cell lines. Cancer Cell Int 15:102

162. Vercellino M, Votta B, Condello C, Piacentino C, Romagnolo A, Merola A, Capello E, Mancardi GL, Mutani R, Giordana MT, Cavalla P (2008) Involvement of the choroid plexus in multiple sclerosis autoimmune inflammation: a neuropathological study. J Neuroimmunol 199:133-141

163. Villares R, Cadenas V, Lozano M, Almonacid L, Zaballos A, Martinez AC, Varona R (2009) CCR6 regulates EAE pathogenesis by controlling regulatory CD4 + T-cell recruitment to target tissues. Eur J Immunol 39:1671-1681

164. Virag J, Haberler C, Baksa G, Piurko V, Hegedus Z, Reiniger L, Balint K, Chocholous M, Kiss A, Lotz G, Glasz T, Schaff Z, Garami M, Hegedus B (2017) Region specific differences of claudin-5 expression in pediatric intracranial ependymomas: potential prognostic role in supratentorial cases. Pathol Oncol Res 23:245-252

165. Wakim LM, Woodward-Davis A, Bevan MJ (2010) Memory T cells persisting within the brain after local infection show functional adaptations to their tissue of residence. Proc Natl Acad Sci USA 107:17872-17879

166. Wolburg H, Wolburg-Buchholz K, Liebner S, Engelhardt B (2001) Claudin-1, claudin-2 and claudin-11 are present in tight junctions of choroid plexus epithelium of the mouse. Neurosci Lett 307:77-80

167. Wolburg K, Gerhardt H, Schulz M, Wolburg H, Engelhardt B (1999) Ultrastructural localization of adhesion molecules in the healthy and inflamed choroid plexus of the mouse. Cell Tissue Res 296:259-269

168. Xiang J, Alesi GN, Zhou N, Keep RF (2012) Protective effects of isothiocyanates on blood-CSF barrier disruption induced by oxidative stress. Am J Physiol Regul Integr Comp Physiol 303:R1-R7

169. Xu YZ, Nygard M, Kristensson K, Bentivoglio M (2010) Regulation of cytokine signaling and T-cell recruitment in the aging mouse brain in response to central inflammatory challenge. Brain Behav Immun 24:138-152

170. Yamamoto M, McCaffery P, Drager UC (1996) Influence of the choroid plexus on cerebellar development: analysis of retinoic acid synthesis. Brain Res Dev Brain Res 93:182-190

171. Zhang ET, Inman CB, Weller RO (1990) Interrelationships of the pia mater and the perivascular (Virchow-Robin) spaces in the human cerebrum. J Anat 170:111-123

172. Zihni C, Mills C, Matter K, Balda MS (2016) Tight junctions: from simple barriers to multifunctional molecular gates. Nat Rev Mol Cell Biol 17:564-580 